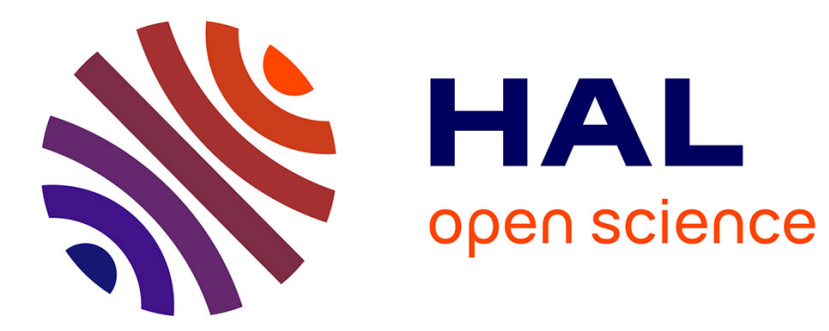

\title{
Robust design strategy applied to a vehicle suspension system with high camber angle tyres
}

\author{
Estelle Koensgen, Sébastien Berger, Christophe Bouet, Louis Jézéquel, \\ Evelyne Aubry
}

\section{- To cite this version:}

Estelle Koensgen, Sébastien Berger, Christophe Bouet, Louis Jézéquel, Evelyne Aubry. Robust design strategy applied to a vehicle suspension system with high camber angle tyres. International Journal of Vehicle Design, 2013, 62 (1), pp.42 - 71. 10.1504/IJVD.2013.051588 . hal-00982583

\section{HAL Id: hal-00982583 \\ https://hal.science/hal-00982583}

Submitted on 24 Apr 2014

HAL is a multi-disciplinary open access archive for the deposit and dissemination of scientific research documents, whether they are published or not. The documents may come from teaching and research institutions in France or abroad, or from public or private research centers.
L'archive ouverte pluridisciplinaire HAL, est destinée au dépôt et à la diffusion de documents scientifiques de niveau recherche, publiés ou non, émanant des établissements d'enseignement et de recherche français ou étrangers, des laboratoires publics ou privés. 


\section{Robust design strategy applied to a vehicle suspension system with high camber angle tyres}

Estelle Koensgen

Renault SAS / Vehicle Dynamics Research Group, 1 av Golf 78280 Guyancourt, France, estelle.koensgen@renault.com

Estelle Koensgen is working in the Vehicle Dynamics Research group of Renault.

Sébastien Berger

MIPS, ENSISA - UHA, 12 rue des frères Lumière 68093Mulhouse Cedex, France, sebastien.berger@uha.fr

fax number: +33 389423282

Sébastien Berger is an Associate Professor in the MIPS laboratory in The Université de Haute-Alsace. He is currently working on the robust approach to dynamical systems, nonlinear dynamics, stability analysis, friction-induced vibrations and robust design

Christophe Bouet

Renault SAS / Vehicle Dynamics Research Group, 1 av Golf 78280 Guyancourt, France, christophe.bouet@renault.com

Christophe Bouet is working in the Vehicle Dynamics Research group of Renault.

Louis Jezequel

LTDS - Equipe D2S, Ecole Centrale de Lyon, 36 Avenue Guy de Collongue, 69134 Ecully Cedex, France,

louis.Jezequel@ec-lyon.fr

fax number: +33 472189144

Louis Jezequel is an Professor in the LTDS laboratory at the Ecole Centrale de Lyon.

$\mathrm{He}$ is currently working on non-linear dynamics, stability analysis, friction-induced vibrations, rotating machinery, vehicle dynamics and robust design

Evelyne Aubry

MIPS, ENSISA - UHA, 12 rue des frères Lumière 68093Mulhouse Cedex, France, evelyne.aubry@uha.fr

fax number: +33 389423282

Evelyne Aubry is an Professor in the MIPS laboratory in The Universite de Haute-Alsace.

She is working on dynamic phenomena, vibrations and rotating machinery. 


\begin{abstract}
This paper presents the robust design of a suspension system suitable for tyres whose camber angle can cover a large interval. The originality of this study is to take account of the tyre camber angle within the range $\left(+/-20^{\circ}\right)$ in the robust design of a vehicle suspension system. The methodology is based on the hierarchical organization of the design process, on simplified models, on sensitivity analysis and on robust optimization. The paper describes the robust design methods, the modelling of the tyre, the design process and the results. Two models of car tyres valid for high camber angles have been defined. The design strategy based on "First Design" and "Rational Design" methods, as well as on the "Electre" decision support method, shows its strong potential for finding efficient and robust solutions. The feasibility of integrating an axle into the steering system at high camber angles is demonstrated.
\end{abstract}

\title{
Keywords
}

quality; robust design; camber angle; tyre; optimization; vehicle dynamics; vehicle suspension system

\section{Introduction}

In the highly competitive sector of the automotive industry, manufacturers must satisfy their customers to gain or maintain market share. They are therefore constantly subjected to the need for innovation in order to improve the environment, comfort, performance and vehicle safety, while respecting their quality objectives, costs and deadlines.

In this context, design strategies must be implemented considering both the performance of the system and its robustness to uncertainties due to the variability of the design parameters and external environment parameters.

Moreover, the control of the wheel plane - especially the camber angle - has hardly been studied, because of the costs and difficulties in the adaptation to existing axle technologies and vehicle integration, despite the important role of camber thrust in dynamic vehicle behaviour (Milliken, 1995).

So, the aim of this paper is to present a robust design strategy applied to a suspension system suitable for tyres whose camber angle can reach high values $\left(+/-20^{\circ}\right)$. The vehicles considered for this study are rather the sports cars. The originality of this paper is to take account of a high camber angle in a robust design strategy based on a hierarchical optimization of the design variables.

To give the reader an overview, all the steps in the strategy process will be presented; However, this paper will more particularly focus on the functional approach and the modeling of high camber tyre. The organic approach will be presented more succinctly with particular emphasis on the method which will allow to choice the suspension system technology.

Section 2 describes two design methods on which the global design strategy is based, section 3 depicts the tyre models which are valid for high camber angles; section 4 presents the global design strategy with the functional design and the results.

For confidentiality reasons, all the details of the different stages proposed are not always given, but the formulation is sufficiently clear to help understand the strategy.

\section{Design methods}

Two design methods called "First Design" and "Rational design - Electre" - on which the global design strategy is based - are presented here. 


\subsection{First Design}

The method called First Design (Chatillon, 2005 and 2006) is based on an engineering system - a V-shaped Cycle - in which the notions of hierarchy of the parameters and models and the notions of robustness and optimization are fundamental.

This method allows the design of complex mechanical systems which must meet the specifications of the product with maximum reliability. It uses the basic idea of the $\mathrm{V}$-shaped Cycle, which consists in defining an optimization strategy based on a hierarchical organization between the functional sets, the functional sub-systems, the components and parts, and in selecting the technical specifications at each stage of the design (Figure 1). The specifications must allow each level of design to be defined independently, so as to obtain detailed drawings for the manufacture of parts.

The use of multi-physics models tailored for each stage of the design allows for different levels of specifications which provide a basis for exchange between the product architectures, the different professions and subcontractors. These models can be classified in three categories:

- the simplified models used in the preliminary phase of the project : they do not require long calculation time and help to explore a wide design area in the optimization process

- the development models, often derived from a finite element model

- the experimental models which help to capitalize the information on the existing systems.

To ensure the quality of the system, the concept of robustness is taken into account at each level of the design cycle. A robust design means a design which is less sensitive to the uncertainties of parameters. So, at each step, the optimization process incorporates the variability of parameters. In the automotive context, uncertainties may have the following origins: the variability of the manufacturing process, the variability of assembling process, the presentation of a vehicle in several configurations, the changing of the design parameter values during the product life and the ageing of the components.

\section{2 “Rational Design and electre" method}

The "Rational design and electre" method is based on both the rational design method (Roy, 1975) and the electre method (Roy, 1978).

The rational method helps to describe and capture the arguments and decisions related to the design of a system. It allows the exploration of alternative design and the explanation of the goals and reasons for the choice; for capitalization, it allows good design traceability for possible future uses. The Rational Design method unfolds as follows:

Rational design is based on rational Question, Options, Criteria (QOC) formalism. Regarding the issue, a specific question $\mathrm{Q}$ is to be answered. Starting from this issue, the technological solutions (options) are listed and built. $\mathrm{n}$ criteria $\mathrm{C}_{\mathrm{k}}$ belonging to categories are then delivered to rate the options and raise the uncertainties of each. Each solution is linked to each criterion $\mathrm{C}_{\mathrm{k}}$ with a mark $\mathrm{f}_{\mathrm{k}}$ compared with a reference solution. A table is thus built:

- if the evaluated solution is better than the reference solution with criterion $\mathrm{C}_{\mathrm{k}}$, the mark $\mathrm{f}_{\mathrm{k}}$ is equal to 1 (gray in the quotation table 1 )

- if the evaluated solution is worse than the reference solution with the criterion $C_{k}$, the mark $\mathrm{f}_{\mathrm{k}}$ is equal to -1 ( in the quotation table 1 )

- if the evaluated solution is the same as reference solution with the criterion $C_{k}$, the mark $f_{k}$ is equal to 0 (no colour in the quotation table 1 ). 
- when the evaluation of the criterion for the new solution is uncertain in comparison with the reference solution, the mark $f_{k}$ is equal to 1 if the expected result should be positive and the mark $\mathrm{f}_{\mathrm{k}}$ is equal to 0 if the expected result should be negative (dark gray in the quotation table 1)

So, the rational design allows the definition of a set of solutions.

Then the electre method which is a protocol of multi-criteria analysis and optimization (Roy, 1978), leads to the ranking of the proposed solutions by the rational design method:

- A weighting $P_{k}$ is assigned for each criterion $C_{k}$.

- For each pair of solution ( $a, b)$ : the marks $a$ and $b$ for each criterion, respectively denoted $\mathrm{f}_{\mathrm{k}}(\mathrm{a})$ et $\mathrm{f}_{\mathrm{k}}(\mathrm{b})$, are compared for the calculation of a concordance index $\mathrm{C}(\mathrm{a}, \mathrm{b})$ :

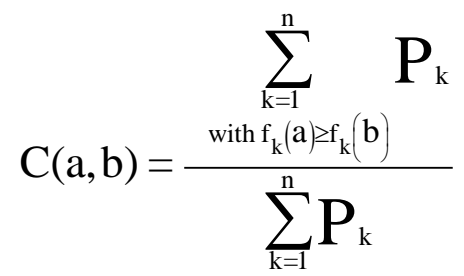

and a discordance index $\mathrm{D}(\mathrm{a}, \mathrm{b})$ :

$$
D(a, b)=\left\{\begin{array}{c}
0 \quad \text { if } f_{k}(a) \geq f_{k}(b), \forall k=1 . . n \\
\text { else } \frac{\max _{k}\left(f_{k}(b)-f_{k}(b)\right)}{2} \text { for } k \text { as } f_{k}(a)<f_{k}(b)
\end{array}\right.
$$

- A concordance threshold denoted c (high enough) and a discordance threshold denoted d (small enough) are specified. They help to define the outclassing relation denoted a S b which means a outclasses b :

$$
\text { a S b if and only if }\left\{\begin{array}{l}
C(a, b) \geq c \\
D(a, b) \leq d
\end{array}\right.
$$

- A graph is built with the outclassing relation a $\mathrm{S}$ b. If a solution denoted a outclasses an other solution denoted $b$, an arrow is drawn from the solution a to solution $b$. This leads to $a$ classification and the best solutions are identified. Figure 2 describes the choice strategy based on the "Rational design and Electre" method.

Section 4 presents a quotation table to illustrate the method. This table shows a few categories and solutions used in the suspension system design.

So, the "Rational design and electre" method helps to choose the best solution.

\section{Tyre modelling}

In this study, it is necessary to define a behaviour model valid for tyres with high camber angles $\left[-20^{\circ}, 20^{\circ}\right]$. The literature provides extensive research work on tyre modelling, but hardly any concerning high camber angles: the few existing studies are about motorcycle tyres (De Vries, 1997) (Biral, 2000) (Tezuka, 2001) (Lot, 2004). 
Two models valid for high camber angles are to be defined - an experimental model based on a Pacejka model and a physical model based on a brush model. Then, the results obtained with the two models are compared and validated.

\subsection{Experimental models}

The idea is to define a car tyre model valid for high camber angles from a tyre model developed by De Vries and Pacejka (De Vries, 1998) for motorcycles (MF-MCTyre) which is valid for such angles.

Compared with Pacejka's traditional car tyre model (MF-Tyre) (Schmeitz, 2004), the variation of the camber angle is taken into account in the MF-MCTyre model by adding terms to the expressions of the longitudinal force Fx, lateral force Fy and auto-alignment torque $\mathrm{Mz}$ in pure side slip. (The new terms are in bold in the equations of the appendix). It must be noted that in this study, only the lateral force Fy is necessary and it is not linear in camber angle.

The values of the motorcycle tyre parameters are highly different from those of cars and involve different behaviours. For example, the side slip stiffness is plotted in according to the vertical load for two car tyre models and one motorcycle tyre model in the Figure 3.

The side slip stiffness is defined by:

$$
\mathrm{C}_{\gamma}=\left.\frac{\partial \mathrm{F}_{\mathrm{y} \gamma}}{\partial \gamma}\right|_{\gamma=0}
$$

with $\mathrm{F}_{\mathrm{y \gamma}}$ the lateral force due to camber angle $\gamma$.

A new set of Pacejka's parameters for a new car tyre model has been identified so that its dynamic behaviour corresponds to a car tyre model (MF-Tyre) which will be as valid as the MF-MCTyre model for high camber angles.

This approach analyzed the sensitivity of the Pacejka's parameters in order to quantify their influence. Then, the most influential parameters has been identified with the Gauss-Newton minimization algorithm (Coleman, 1994). The identification of these new parameters is performed from the motorcycle tyre parameters in minimizing the least-square error about the lateral force calculated from the results obtained respectively with new car tyre model and car tyre model (MF-Tyre) for low camber angles. As the only lateral force Fy is necessary, figure 4a presents the lateral force according to side slip for Pacejka's classic car tyre model and the new car tyre model valid for high camber. Moreover, Figure $4 \mathrm{~b}$ presents the lateral force according to camber angle for Pacejka's classic car tyre model and the new car tyre model valid.

A first Pacejka model suitable for car tyres with high camber and a side slip angle in the range of $\left[-4^{\circ}, 4^{\circ}\right]$ is thus obtained.

\subsection{Brush model}

\subsubsection{Presentation}

The Brush model is a physical model (Gim, 1991), (Svendenuis, 2003) based on the decomposition of the tyre into a range of flexible rubber elements obtained by splitting the tread (Figure 5). It is assumed that the elements are isotropic and that the longitudinal and transverse stiffnesses are identical (Ratti, 1986). Each element in contact with the ground deforms independently, lengthwise and crosswise. In the sliding area, each element begins to 
slide in contact with the ground and the generated forces are independent of the deformations of each element (Figure 6).

The longitudinal forces $\mathrm{F}_{\mathrm{x}}$ and lateral forces $\mathrm{F}_{\mathrm{y}}$ are expressed in terms of longitudinal $\mathrm{C}_{\mathrm{PX}}$ and lateral $\mathrm{C}_{\mathrm{PY}}$ shear stiffness per unit length of the rubber (1):

$$
\left\{\begin{array}{l}
\mathrm{F}_{\mathrm{x}}(\mathrm{x})=\int_{x_{s}}^{a} \mathrm{dF}_{\mathrm{x}}(\mathrm{x})=-\mathrm{c}_{\mathrm{px}} \sigma_{\mathrm{x}} \int_{x_{s}}^{a}(\mathrm{a}-\mathrm{x}) \mathrm{dx} \\
\mathrm{F}_{\mathrm{y}}(\mathrm{x})=\int_{x_{s}}^{a} \mathrm{dF}_{\mathrm{y}}(\mathrm{x})=-\mathrm{c}_{\mathrm{py}} \sigma_{\mathrm{y}} \int_{x_{s}}^{a}(\mathrm{a}-\mathrm{x}) \mathrm{dx}
\end{array}\right.
$$

with $x_{s}$ the abscissa at the limit of the adhesion area,

$\sigma_{x}$ and $\sigma_{y}$ respectively the longitudinal and transverse slip rates.

$2 * a$ the length of the contact area

The size of the grip zone is determined by the available static friction. When the elementary forces $\mathrm{dFx}$ and $\mathrm{dFy}$ are superior to the constraints of static friction, the rubber element starts to slip. Taking account of a pressure distribution in the contact area, the point where the slide appears is identified. The pressure distribution along the length of the contact area is considered parabolic. Indeed the trapezoidal distribution is closer the reality but numerical results are better with a parabolic distribution (Ratti, 1986). The bending rigidity is assumed uniform across the width of the tread. The brush model is used with three rows of elements in order to take the change in the camber angle into account (Figure 7).

The longitudinal force $F_{x}$, lateral force $F_{y}$ and auto-alignment torque $M_{z}$ can be determined from the forces along the contact area. However, these depend on the longitudinal $\mathrm{C}_{\mathrm{PX}}$ and lateral $\mathrm{C}_{\mathrm{PY}}$ shear stiffness of the rubber elements.

\subsubsection{Shear stiffness measurements}

The longitudinal $\mathrm{C}_{\mathrm{PX}}$ and lateral $\mathrm{C}_{\mathrm{PY}}$ shear stiffnesses were identified from measurements made on samples extracted from the tread of the tyre. The experiments were conducted using a hydraulic actuator, the record entry being the displacement of the actuator and the output the stabilized force (Figure 8). The pressure distribution at the contact area was imposed by tightening the jaws of the hydraulic actuator with a chosen pressure which was measured from a pressure sensor located between the rubber element and the jaw. To check the influence of the speed, the displacement of the actuator was performed with different displacement steps for the same given time. Figure 9 shows the lateral forces according to the displacements with four different displacement steps. A hysteresis is generated by an energy dissipation. Nevertheless, for the sake of simplification, the histeresis effect of the experiments was neglected. From these curves, the shear stiffnesses were identified and plotted as a function of the displacement step (Figure 10). The measurements show that the experimental values of the shear stiffnesses depend on the value of the displacement step, that is to say of the needs. Moreover, for the same displacement step, the stiffnesses of longitudinal and transverse shear show quite similar values which are relatively constant, especially for large displacement steps. The assumption made in the literature (Pacejka, 2006) about these two identical stiffnesses is verified. 


\subsection{Comparison of the brush model and the experimental model}

There is a good correlation between the results of the two models used as a simplified model. For example, Figure 11a shows the lateral forces respectively, according to the side slip for the Pacejka model suitable for car tyres with high camber and the brush model whose shear stiffnesses were measured. So, these two models are similar for a side slip angle in the range of $\left[-4^{\circ}, 4^{\circ}\right]$ with high camber angle. Figure $11 \mathrm{~b}$ shows the lateral forces respectively, according to the camber angle for the Pacejka model suitable for car tyres with high camber and the brush model. So, these two models are similar for high camber angle. So, the Pacejka model suitable for high camber will be used as a simplified model in the functional approach of the robust design process of vehicle suspension. As mentioned above, the brush model and the experimental model are non linear camber model.

\section{Design strategy}

The robust First design method is based on a hierarchical optimization of the design parameters in two stages: the functional stage and the organic stage.

The functional stage concerns the hierarchical organization and optimization of functional parameters by taking account of the driving objectives and the constraints of the road : the specifications of the suspension system are divided into functional parameters optimized for specific driving situations

The organic stage allows to division into organs and parts, all optimized functional data according to the ambitions of robust design. The functional optimized parameters become the target parameter of the organic phase.

\subsection{Functional approach}

The functional stage includes the following steps:

The main functions performed by the suspension system are identified.

A hierarchy of functional parameters is established with order one parameters and order two parameters.

The specific driving situations and the objective criteria are defined.

The simplified models simulating the specific driving situations are determined.

The optimization process is carried out in three stages:

- the definition of the design area : this space is defined by the range imposed on parameters for optimization. Its boundaries are determined by considering technologically allowable values in terms of design.

- the robust optimization of the order one parameters which are most influential, from the simplified models and objective criteria related to the specific driving situations. The validation of the results is obtained with the Renault's functional model called "Modeling in Advanced Automotive Dynamics (MADA)". Data about this model are given below.

- the introduction and robust optimization of order two parameters, once the order one parameters were determined with the model MADA.

Figure 12 shows all the necessary elements of the functional phase. It must be noted that this purely functional optimization presupposes neither a particular structural design nor the choice of technological solutions. 


\subsubsection{Main functions}

There are three main functions of a suspension system at this level of optimization: - the kinematic function, determined by the topology of the axle, the position of its kinematic points and the geometric constraints and joints. The kinematic parameters concern mainly variations of steering and camber angles, of longitudinal and transverse displacements during the vertical symmetric and dissymmetric movements of the wheels.

- the elasto-kinematic function which concerns the variations of steering and camber angles, of longitudinal and transverse displacements during the application of forces and torque through the tyres by taking account of the elastic links and flexibility of mechanic parts.

- the flexibility function split into two contributions : the roll flexibility described through anti-roll global stiffness parameters (stiffness of anti-roll bar, linear stiffness of axle) and the vertical flexibility (flexibilities of the suspension system)

Other functions of the suspension system, such as vibration comfort, are not addressed at this design level.

\subsubsection{Functional parameters, specific driving situations, objective criteria, simplified models} The optimization of functional parameters is based on an objective assessment of the dynamic behaviour of the system. The specific driving situations with the most influential parameters, their modelling and objectification are presented here. The objectification of benefits is a new opening in the automotive industry (Gobbi, 1999). The specific driving situations which have been chosen are the "Sinus Ford" and steady state cornering, as the lateral dynamic behaviour is involved significantly.

\subsubsection{Transient behaviour}

The specific driving situation chosen to need the transient lateral behaviour of the vehicle is the Sinus Ford. It is an amplified sinusoidal excitation of the steering wheel angle. The car travels in a straight line at a speed of $100 \mathrm{~km} \cdot \mathrm{h}^{-1}$, then the steering wheel angle describes the curve shown in Figure 13. The amplitude A is determined from a preliminary simulation in which the steering wheel angle increases through a very slow ramp from $0^{\circ}$ to $100^{\circ}$. A is the amplitude of the steering wheel angle when the transverse acceleration of the vehicle is equal to $3 \mathrm{~m} \cdot \mathrm{s}^{-2}$.

The most influential order one parameters which are optimized are :

- the design variables of the axle system (stiffness of anti-roll bars, suspension dampers, steering coefficient induced by roll, height of the roll centre from the ground, camber coefficient induced by the roll, linear castor on the ground, linear stiffness of suspension springs for the axle, sway radius,

- the flexibilities of the suspension system

- the geometric variables as the tracks

Moreover, the order one parameters and the state variables which appear in the simplified model are:

- the physical variables (roll angle, yaw angle, the side slip angle of the centre of gravity of the vehicle, the transverse acceleration of the centre of gravity, the vehicle speed ),

- the variables on the vehicle (mass $\mathrm{M}$, inertia),

- the geometric variables (height $h$ in the centre of gravity, the wheelbases, the tracks),

- the variable of guidance (steering angle, gear ratio), 
- the variables of the tyres (linear side slip rigidities of tyres, camber load coefficient for the front or rear axle, tyres castor angle, camber angle of the tyres, the side slip angles of the tyres for the axles, the stiffness of the tyres for the axles, the nominal load for a wheel)

- the lateral forces for the wheels of the axles

All the parameters are given in the appendix C.

The simplified model considered is a "4-wheel roll / yaw / side slip" model with camber contribution. The equations are given in the appendix B. This model takes account of the report of load and the law of high camber control (Figure 14). The experimental tyre model valid for high camber types is used in order to calculate the lateral forces for the wheels of the axles.

The two objective criteria chosen for optimization which assess the effectiveness and stability of the vehicle are respectively the transverse acceleration and the side slip in the centre of gravity. The performance of a vehicle is defined as its ability to maintain a faithful response to the instruction given by the driver. In the case of the Sinus Ford, this ability is studied in a first change of direction in which maximum acceleration is required (Figure 15). The criterion for assessing the stability of the vehicle is the side slip to the centre of gravity during the second change of direction. The maximum value of the side slip angle is not significant for assessing stability, because it does not present the total value of side slip after the second change of direction. Since the second part of the order destabilizes the vehicle, the integral of the side slip in the centre of gravity in the second change of direction must be calculated in order to assess the ability of the car to return to stable conditions (Figure 16).

In short, the two objective criteria are the maximum acceleration in the first change of direction for the effectiveness and the integral of the side slip in the centre of gravity in the second change of direction for stability. Thus, the maximum acceleration should be maximal and the integral of the side slip should be minimal.

To validate the simplified model, the correlation of objective criteria obtained with the simplified model and the Renault's complete model (MADA) must be verified. This software developed by Renault is based on kinematic, elastokinematic and flexibility maps. The latter are built from experimental measurements and calculations obtained with the ADAMS software.

Using experimental planes in the design space with the simplified model and the full model (MAAD), the two studies lead to the same linear determination of criteria (Figure 17). The correlation indices are respectively equal to 0.9481 for effectiveness and 0.9244 for stability. It appears that a linear graph does not run exactly through the origin. Nevertheless, this difference is low and fair for a simplified model. So, the order one parameters can be optimized with the simplified model. Moreover, the optimization of order two parameters which will occur in the optimization process of the functional parameters with the complete MAAD model, will improve the results.

\subsubsection{Quasi-Steady state behaviour : quasi-Steady state cornering}

In stationary conditions, the state vector of the vehicle is constant in time and the equations of motions are simpler. According to simplified hypothesis, the oversteering (or understeering) rate can be obtained.

This oversteering rate, also called stability factor, is $R$ in the equation (6). $R$ is a function of several functional design parameters. It is defined as the differential of the steering angle $\alpha_{v}$ against the transverse acceleration $\gamma_{t}$, for a constant radius of trajectory $r$ and a variable speed. 
It corresponds to the correction of the steering angle necessary for keeping a circular trajectory when a variation of speed induces a variation of transverse acceleration.

$$
R=\left.\frac{\partial \alpha_{v}}{\partial \gamma_{t}}\right|_{r=\text { constant }}
$$

This stability factor is the sum of several contributions related to the rigidities of the tyres, the kinematics and the elasto-kinematic suspension system.

The parameters are the same as the ones used with the sinus ford.

The simplified model used is a particular case of the transient model presented earlier, where the variables following were cancelled: the angular roll velocity and acceleration, the angular yaw acceleration, the velocity angular side slip, the velocity angular side slip of the tyres for the axles.

The objective criteria chosen for the optimization of vehicle performance in steady state cornering are four specific variables:

- the roll $\theta_{\text {sp }}$ per unit of transversal acceleration:

$$
\theta_{\mathrm{SP}}=\left.\frac{\partial \theta}{\partial \gamma_{t}}\right|_{r=\mathrm{constant}}
$$

with $\theta$ the roll angle

- the side slip $\delta_{1 \mathrm{SP}}$ of the front axle system per unit of transversal acceleration:

$$
\delta_{1 \mathrm{SP}}=\left.\frac{\partial \delta_{1}}{\partial \gamma_{t}}\right|_{r=\mathrm{constant}}
$$

with $\delta_{1}$ the side slip angle for the front axle

- the side slip- $\delta_{2 S P}$ of the rear axle system per unit of transversal acceleration:

$$
\delta_{2 \mathrm{SP}}=\left.\frac{\partial \delta_{2}}{\partial \gamma_{t}}\right|_{r=\mathrm{constant}}
$$

with $\delta_{2}$ the side slip angle for the rear axle

- Stability factor R.

For each of these criteria, targets are set to improve the performance and behaviour of the vehicle. So, the specific roll and the stability factor must reach a target while the specific side slips (front and rear) should be minimal.

To validate the simplified model, the correlation of objective criteria obtained with the simplified model and the Renault's complete model (MADA) is verified (Figure 18). The correlation indices are respectively equal to 0.9368 for stability factor, 0.9531 for specific roll, 0.9478 for specific side slip of the front axle system and 0.9435 for specific side slip of the 
rear axle system. The figure 18 shows that the simplified model and the Renault's complete model generate the same tendency, so the simplified model can be used to carry out a functional optimization of the order one parameters. The same remark about the results as for the sinus ford can be made.

\subsubsection{3 eigenfrequencies}

Frequency constraints are added to the above criteria. For the sake of simplicity, the movements are considered independently of each other.

- Bounce eigenfrequencies $\mathrm{F}_{\text {bounce, } \mathrm{i}}$ for the front and rear axles

Assuming that the chassis is linked to the carriageway by equivalent stiffness in the vertical plane, the bounce frequencies are determined by considering the stiffness of tyres and suspension springs in parallel;

$$
\begin{aligned}
& \mathrm{F}_{\text {Bounce, } \mathrm{i}}=\frac{1}{2 \pi} \cdot\left(\frac{2 \cdot \mathrm{k}_{\mathrm{i}} \cdot \mathrm{k}_{\text {tyre }}}{\mathrm{M}_{\mathrm{i}} \cdot\left(\mathrm{k}_{\mathrm{i}}+\mathrm{k}_{\text {tyre } \mathrm{i}}\right)}\right)^{1 / 2} \\
& \text { with } \mathrm{M}_{\mathrm{i}} \text { mass of axle } \mathrm{i} \text { (front or rear) } \\
& \mathrm{k}_{\mathrm{i}} \text { linear stiffness of suspension springs for the axle } \mathrm{i} \text { (front or rear axle) } \\
& \mathrm{k}_{\text {tyre } \mathrm{i}} \text { stiffness of tyres for the axle } \mathrm{i} \text { (front or rear axle) }
\end{aligned}
$$

- Pitch eigenfrequency $\mathrm{F}_{\text {pitch }}$

$$
\begin{aligned}
& \mathrm{F}_{\text {pitch }}=\frac{1}{2 \pi} \cdot\left(\frac{\mathrm{k}_{\mathrm{t}}}{\mathrm{I}_{\mathrm{y}}}\right)^{1 / 2} \\
& \text { with } \mathrm{k}_{\mathrm{t}} \text { stiffness of pitch } \\
& \mathrm{k}_{\mathrm{t}}=2 \cdot \mathrm{k}_{1} \cdot \mathrm{l}_{1}^{2}+2 \cdot \mathrm{k}_{2} \cdot \mathrm{l}_{2}^{2} \\
& \mathrm{k}_{\mathrm{i}} \text { linear stiffness of suspension springs for the axle } \mathrm{i} \text { (front or rear) } \\
& 1_{\mathrm{i}} \text { distance between the axle } \mathrm{i} \text { (front or rear) and the centre of gravity of the car } \\
& \mathrm{I}_{\mathrm{y}} \text { Inertia of pitch }
\end{aligned}
$$

- Roll eigenfrequency $\mathrm{F}_{\text {roll }}$

$$
\begin{aligned}
& \mathrm{F}_{\text {roll }}= \frac{1}{2 \pi} \cdot\left(\frac{\mathrm{k}_{\mathrm{r}}}{\mathrm{I}_{\mathrm{x}}}\right)^{1 / 2} \\
& \text { with } \mathrm{k}_{\mathrm{r}} \text { stiffness of roll } \\
& \mathrm{k}_{\mathrm{r}}=\frac{1}{4}\left(2 \mathrm{k}_{1} \mathrm{e}_{1}^{2}+2 \mathrm{k}_{2} \mathrm{e}_{2}^{2}\right)+\mathrm{C}_{\text {bad1 }}+\mathrm{C}_{\mathrm{bad} 2} \\
& \mathrm{k}_{\mathrm{i}} \text { linear stiffness of suspension springs for the axle } \mathrm{i} \\
&\left.\mathrm{e}_{\mathrm{i}} \quad \text { (front } \mathrm{i}=1 \text {, rear } \mathrm{i}=2\right) \text { track } \\
& \mathrm{C}_{\text {badi }} \text { anti-roll bar stiffness for the axle } \mathrm{i} \\
& I_{x} \text { Inertia of roll }
\end{aligned}
$$

- Deflection eigenfrequency $\mathrm{F}_{\text {vertical lift }}$ for the front and rear wheels 


$$
\begin{aligned}
& \mathrm{F}_{\text {vertical lift }}=\frac{1}{2 \pi} \cdot\left(\frac{\mathrm{k}_{\text {tyre i }}}{\mathrm{M}_{\mathrm{nsi}}}\right)^{1 / 2} \\
& \text { with } \mathrm{M}_{\mathrm{nsi}} \text { unsprung mass for the axle } \mathrm{i} \text { (front or rear) } \\
& \mathrm{k}_{\mathrm{tyre}} \text { stiffness of tyres for the axle } \mathrm{i} \text { (front or rear) }
\end{aligned}
$$

The optimization process is performed under constraints: the values of eigenfrequencies must be in given intervals.

$$
\begin{aligned}
& \mathrm{F}_{\text {bounce, } \mathrm{i}}^{\min } \leq \mathrm{F}_{\text {bounce, } \mathrm{i}} \leq \mathrm{F}_{\text {bounce, } \mathrm{i}}^{\max } \\
& \mathrm{F}_{\text {pitch }}^{\min } \leq \mathrm{F}_{\text {pitch }} \leq \mathrm{F}_{\text {pitch }}^{\max } \\
& \mathrm{F}_{\text {roll }}^{\min } \leq \mathrm{F}_{\text {roll }} \leq \mathrm{F}_{\text {roll }}^{\max } \\
& \mathrm{F}_{\text {verticallift }}^{\min } \leq \mathrm{F}_{\text {vertical lift }} \leq \mathrm{F}_{\text {vertical lift }}^{\max }
\end{aligned}
$$

with $\mathrm{F}_{\text {bounce, }}^{\min }, \mathrm{F}_{\text {bounce,i }}^{\max }, \mathrm{F}_{\text {pitch }}^{\min }, \mathrm{F}_{\text {pitch }}^{\max }, \mathrm{F}_{\text {roll }}^{\min }, \mathrm{F}_{\text {roll }}^{\max }, \mathrm{F}_{\text {verticallift }}^{\min }, \mathrm{F}_{\text {vertical lift }}^{\max }$

the given limited frequencies

\subsubsection{Cost functions}

For each specific driving situation, a comprehensive performance function $f_{\text {perf }}$ describes the performance of the system corresponding to the sum of the normed differences between each value of the criteria defined above and their corresponding targets (15):

$$
\begin{array}{r}
\mathrm{f}_{\text {perf }}=\sum_{\mathrm{i}=1}^{\mathrm{n}}\left|\mathrm{f}_{\mathrm{ci}}\right| \\
\text { with } \mathrm{f}_{\mathrm{ci}}=\frac{\mathrm{c}_{\mathrm{i}}-\mathrm{c}_{\mathrm{i}}{ }^{*}}{\overline{\mathrm{c}}_{\mathrm{i}}-\mathrm{c}_{\mathrm{i}}{ }^{*}}
\end{array}
$$

with $c_{i}$ the criterion, $c_{i}^{*}$ the target value in the design space and $\bar{c}_{i}$ the worst value in the design space. The values respectively of $c_{i}{ }^{*}$ and $\bar{c}_{i}$ are chosen by the expert designers from their professional experience. For confidentiality reasons, no more details can be specified; in particular, the values of these parameters cannot be given. As the optimization process is carried out under constraints imposed on the natural frequencies of the vehicle, the objective space of the system is not a linear space. The optimal design does not always occur on the boundary.

In addition, for each specific driving situation a robustness function $\mathrm{f}_{\text {rob,ci }}^{\mathrm{p}_{\mathrm{j}}}$ is defined for each candidate for optimization for each parameter $\mathrm{P}_{j}$ and criterion $\mathrm{c}_{\mathrm{i}}$ as follows:

$$
\mathrm{f}_{\text {rob,ci }}^{\mathrm{p}_{\mathrm{j}}}=\max \left\{\begin{array}{c}
\left|\mathrm{f}_{\mathrm{ci}}\left(\mathrm{p}_{\mathrm{j}}=\mathrm{p}_{\text {jnominal }}\right)-\mathrm{f}_{\mathrm{ci}}\left(\mathrm{p}_{\mathrm{j}}=1.1 * \mathrm{p}_{\mathrm{j} \text { nominal }}\right)\right|, \\
\left|\mathrm{f}_{\mathrm{ci}}\left(\mathrm{p}_{\mathrm{j}}=\mathrm{p}_{\text {jnominal }}\right)-\mathrm{f}_{\mathrm{ci}}\left(\mathrm{p}_{\mathrm{j}}=0.9 * \mathrm{p}_{\mathrm{j} \text { nominal }}\right)\right|, \\
\left|\mathrm{f}_{\mathrm{ci}}\left(\mathrm{p}_{\mathrm{j}}=0.9 * \mathrm{p}_{\text {jnominal }}\right)-\mathrm{f}_{\mathrm{ci}}\left(\mathrm{p}_{\mathrm{j}}=1.1 * \mathrm{p}_{\mathrm{j} \text { nominal }}\right)\right|
\end{array}\right\}
$$

with $\mathrm{p}_{\text {jnominal }}$ the nominal value of the parameter $\mathrm{p}_{\mathrm{j}}$ 
Then an overall robustness function $\mathrm{f}_{\text {rob,ci }}$ is defined for each candidate for optimization for each criterion $\mathrm{c}_{\mathrm{i}}$ as follows:

$$
\mathrm{f}_{\text {rob,ci }}=\sum_{\mathrm{j}=1}^{\text {all parameters }} \mathrm{f}_{\text {rob,ci }}^{\mathrm{p}_{\mathrm{j}}}
$$

Then, for each specific driving situation, an overall robustness function $\mathrm{f}_{\text {rob,situation }}$ is defined for each candidate for optimization as follows:

$$
\mathrm{f}_{\text {rob,situation }}=\sum_{\mathrm{i}=1}^{\text {all criteria }} \mathrm{f}_{\text {rob,ci }}
$$

\subsubsection{Functional optimization}

Once the design space has been defined, the optimization of the design parameters is carried out in two stages.

\subsubsection{Optimization of order 1}

The robust optimization of the most influential parameters of order 1 , based on simplified models and objective criteria related to the driving situation is performed from a multiobjective genetic algorithm so as to converge on the Pareto front which represents the tradeoff between the different criteria for each driving situation (Sastry, 1999). The algorithm does not converge to a unique solution but to a frontier (Pareto front). A point is chosen as a Pareto solution if no criterion can be improved without decreasing at least one other criterion. The algorithm is based on the principles of genetic algorithms and on the notion of Pareto front (Chatillon, 2006) (Messac, 2003) (Zhang, 2000). The set of Pareto solutions is determined from amongst the random population of the first generation of the algorithm. Then the aim is to increase the number of Pareto solutions and to improve their distribution in the fitness function space over the following generations. The modified fitness depends on the position of the newly generated solution, taking into consideration the existing set of Pareto solutions. According to the nature of the solution (new Pareto point or not), the fitness value is modified in order to favour, on the one hand, the new Pareto solutions and, on the other hand, the Pareto solutions well distributed on the existing Pareto front. The different genetic standard operators of crossover and mutation (Houck,1995) are then applied on the modified fitness values and naturally favour the selection of the Pareto solutions which are well-distributed in the fitness value space. So the algorithm tends to converge on a wide front of Pareto solutions, exploitable by the engineer.

The camber law is introduced at this level of study. The camber map is in the form of a polynomial depending on the steering wheel angle and lateral acceleration. These two only parameters are the inputs in the polynomial because according to the expert designers these parameters are very influential and too many inputs must be avoided. The degree of the polynomial has been optimized and set at two for the steering wheel angle and three for acceleration. So, along with the design parameters of order 1, the polynomial coefficients of the control law are also added in the optimization process.

An algorithm including 200 individuals evolving over 100 generations has resulted in a Pareto front with the objective functions $f_{\mathrm{ci}}$ for the driving situations (Figure 19a, Figure 19b). Figure 19a represents the Pareto front for two criteria of Sinus ford. Figure 19b represents the 
Pareto front for 3 out of 4 criteria of steady state cornering. The Pareto front (asterisk points) and the sub-optimal point (triangle) are represented.

The optimization of the two driving situations was carried out with the comprehensive performance function $f_{\text {perf }}$ in order to find the best compromise (Figure 20). The sub-optimal point (triangle) for a steady state cornering / Sinus Ford compromise is selected by the designer.

Generally, the cost functions $\mathrm{f}_{\text {perf }}$ have been improved from $10 \%$ to $30 \%$ versus the starting point design.

In addition to this compromise, a study of robustness is introduced at this stage, thanks to the low cost of simulations with the simplified models. For each criterion and each candidate received with the genetic optimization, the robustness function $\mathrm{f}_{\text {rob,ci }}^{\mathrm{p}_{\mathrm{j}}}$ of criteria ci (objective functions $f_{c i}$ ) is calculated for each parameter $\mathrm{P}_{\mathrm{j}}$. For example, the robustness function $\mathrm{f}_{\mathrm{rob}, \mathrm{ci}}^{\mathrm{p}_{\mathrm{j}}}$ for steady state cornering. A response to a change in the functional parameters $p_{j}$ is shown in Figure 21. Each square represents the robustness function $\mathrm{f}_{\text {rob,ci }}^{\mathrm{p}_{\mathrm{j}}}$ of a test vehicle for a variation of a given parameter. The clearer the square is, the greater robustness is.

The overall robustness function $\mathrm{f}_{\text {rob,ci }}$ defined for each candidate for optimization for each criterion $\mathrm{c}_{\mathrm{i}}$ can be calculated. It helps to evaluate the ability to provide the same performance despite changes in the parameters values for a criterion. And the overall robustness function $\mathrm{f}_{\text {rob,situation }}$ can also be calculated for each candidate received at the conclusion of the genetic optimization, considering several driving situations.

Finally, the best candidate can be chosen by taking account of the comprehensive performance function $\mathrm{f}_{\text {perf }}$ and the overall robustness function $\mathrm{f}_{\text {rob,situation }}$ in order to find the best compromise for a given type of vehicle.

The rapidity of simulation also allows low-cost studies of robustness in the preliminary phases of project and helps to select the least sensitive points among the interesting points obtained during the optimization process. It must be noted that the order one parameters were not optimized with the model called MADA, as the computation time would have been too high. The time spent for optimization is a few minutes with the simplified model and a few days with the complete model (MADA).

\subsubsection{Optimization of order 2}

The last stage in the optimization process of the functional parameters concerns the least influential order 2 parameters. These are all parameters which are not directly in the simplified model and which are taken into account with the full MADA model. The experimental tyre model valid for high camber types is used with full MADA model.

The order 1 parameters being set, the order 2 parameters are optimized with genetic algorithms, which provides Pareto fronts. 


\subsection{Physical approach}

After the functional stage, the organic approach allows the optimized functional data to be divided into organs and parts. The functional optimized parameters become the target parameter of the organic phase. The material parameters have to be optimized to satisfy the specifications imposed by the functional optimization. As mentioned in the introduction, the organic approach will not be presented in much detail.

\subsubsection{Organic technology}

Now, a technology and architectural description of the system must be chosen in order to perform the organic optimisation. As explain in section 2, the combination of the Rational Design method and the Electre method allows the choice of the best suited architecture for the integration of high camber. Regarding the issue, technological solutions (options) were listed, criteria belonging to categories were built and weighting coefficient were defined. Part of the quotation table is given as an illustration (table 1). Nevertheless, for confidentiality reasons, all the criteria, categories and solutions are not described, but the strategy can still be understood. The best architecture obtained with this method is the double wishbone axle with a Semi-Fictitious Pivot called SFP (Patent No. FR2890631) (Figure 22). The innovation is to board the steering on the upper arm and to control the camber angle.

\subsubsection{Organic parameters and optimization}

The optimization phase of the organic parameters is divided into the optimization of the bodies and the parts respectively, in the suspension system (Figure 23).

From the functional optimized parameters, the first step helps to find the bodies which can provide the main functions of a suspension system. Relying on the architecture of the SFP suspension system, all the topology must be established taking account of the constraints imposed by the project. Each body is defined by simplified geometric and physical parameters.

The second step is the more precise calculation of each part of the suspension system from the optimized bodies parameters. At this stage of design, the performance criteria of mechanical resistance and endurance are introduced, considering the functions of the system suspension: the kinematic function, that is to say the steering of the wheel plane, the elasto-kinematic function which is due to the elastic links and stiffness of metal parts, the flexibility function.

\section{Conclusion}

This paper has proposed a robust design strategy for a suspension system suitable for tyres whose camber angle can cover a wide range $\left[-20^{\circ}, 20^{\circ}\right]$. Two car tyre models valid for high camber angles have been defined. The design strategy based on several methods called "First Design", "Rational Design", and "Electre" method, has shown its strong potential for finding solutions which are both efficient and robust. This strategy is based on a hierarchical organization of the design parameters and the models. This process also allows the management of compromises. Finally, the study has highlighted the feasibility of designing an axle suitable for high camber angles.

\section{Bibliography}

F. Biral, R. Berrita, S. Garbin,2000, Evaluation of motorcycle handling with multibody modeling and simulation, In: Proceedings of $6^{\text {th }}$ int. conference on high tech engines and cars, Modena, 2000. 
M.M. Chatillon, L. Jezequel, P. Baggio, P. Coutant, 2005, Robust Design Strategy applied to vehicle suspension system, $17^{\text {th }}$ International Conference on Design Theory and Methodology, Long Beach, CA, USA, 24-28, September

M.M. Chatillon, L. Jezequel, P. Coutant, P. Baggio, 2006, Hierarchical optimization of the design parameters of a vehicle suspension system, Vehicle System Dynamics, 44 (11), p 817-839

T.F. Coleman, Y. Li, 1994, On the convergence of interior-reflective Newton methods for large-scale-nonlinear minimization subject to bounds, Mathematical Programming, Vol. 67, $\mathrm{n}^{\circ}$ 1-3, 189-224, DOI: 10.1007/BF01582221

E.J.H. De Vries, H. B. Pacejka, 1998, Motorcycle tyre measurements and models, Vehicle System Dynamics, vol. 9, p. 280-298

G. Gim, P.E. Nikravesh, 1991, An analytical model of pneumatic tyres for vehicle dynamic simulations, part2: Comprehensive slips, Int. J. of Vehicle Design, vol. 12, n. 1, P. 19-39

M. Gobbi, G. Mastinu, C. Doniselli, 1999, Optimising a car chassis, vehicle system dynamics, vol. 32, n. 2-3, p. 149-170, August

C. R. Houck, J. A. Joines, M. G. Kay, 1995, A genetic algorithm for function optimization: A matlab implementation, North Carolina State University - Department of Industrial Engineering, Technical Report 9509.

Y. Tezuka, H. Ishii, S. Kiyota, 2001, Application of the magic formula tyre model to motorcycle maneuverability analysis, JSAE Review, Vol. 22(3), pp.305-310, July 2001.

R. Lot, 2004, A motorcycle tyre model for dynamic simulations: Theoretical and experimental aspects, Meccanica, Vol. 39, n 3, june, pp.207-220(14).

A. Messac, A. Ismail-Yahaya, C.A. Mattson, 2003, The Normalized Normal Constraint Method for Generating the Pareto Frontier, Structural and Multidiscplinary Optimization, vol. 25, n² 2, p. 86-98, DOI: 10.1007/s00158002-0276-1

W. F. Milliken, D.L. Milliken, 1995, Race car vehicle dynamics, SAE International, Warrendale

H. B. Pacejka, 2006, Tyre and vehicle dynamics, SAE International, $2^{\text {nd }}$ edition.

P. Ratti, 1986, Modélisation du pneumatique pour l'étude du comportement routier des véhicules automobiles, $\mathrm{PhD}$ thesis, Ecole Nationale d'Art et Métiers de Paris, France

B. Roy, 1975, Vers une méthodologie générale d'aide à la décision, Revue METRA, vol. 14, n³, pp. $456-497$.

B. Roy, 1978, Electre III : un algorithme de classement fondé sur une représentation floue des préférences en présence de critères multiples, Cahiers du CERO, 20(1):3-24,

V.N. Sastry, S. Mohideen, S. Ismail, 1999, A modified Algorithm to Compute Pareto-optimal Vectors, Journal of optimization theory and applications, USA, vol.103, $\mathrm{n}^{\circ} 1, \mathrm{pp} .241-244$

A.J.C. Schmeitz, S. TH. Jansen, I.J.M. Besselink, H.B. Pacejka, 2004, The swift tyre model: overview and applications, 7th international symposium on advanced vehicle control, Arnhem, Netherlands, pp. 525-530.

J. Svendenius, B. Wittenmark, 2003, Review of Wheel Modelling and Friction Estimation, Department of Automatic Control, Lund institute of technology, Sweden.

J. Zhang, M.M. Wiecek, W. Chen, 2000, Local approximation of the efficient frontier in robust design, Journal of Mechanical Design, 122, 232-244.

\section{Appendix}

A- Motorcycle Pacejka Model, MF-McTyre (Biral, 2000) (Pacejka, 2006)

Lateral force in pure side slip

$$
\begin{aligned}
\mathrm{F}_{\mathrm{y} 0}=\mathrm{D}_{\mathrm{y}} \cdot \sin \left[\mathrm{C}_{\mathrm{y}} \cdot \arctan \left\{\mathrm{B}_{\mathrm{y}} \cdot \alpha_{\mathrm{y}}-\mathrm{E}_{\mathrm{y}} \cdot\left(\mathrm{B}_{\mathrm{y}} \cdot \alpha_{\mathrm{y}}-\arctan \left(\mathrm{B}_{\mathrm{y}} \cdot \alpha_{\mathrm{y}}\right)\right)\right\}\right. \\
\left.+\mathbf{C}_{\boldsymbol{\gamma}} \cdot \arctan \left\{\mathbf{B}_{\boldsymbol{\gamma}} \cdot \boldsymbol{\gamma}_{\mathbf{y}}-\mathbf{E}_{\boldsymbol{\gamma}} \cdot\left(\mathbf{B}_{\gamma} \cdot \boldsymbol{\gamma}_{\mathbf{y}}-\arctan \left(\mathbf{B}_{\gamma} \cdot \boldsymbol{\gamma}_{\mathbf{y}}\right)\right)\right\}\right]
\end{aligned}
$$

with

$$
\alpha_{\mathrm{y}}=\alpha^{*}+S_{H y} \quad \gamma_{\mathrm{y}}=\gamma \cdot \lambda_{\gamma y} \quad \mathrm{~B}_{\mathrm{y}}=\frac{\mathrm{K}_{\mathrm{y} \alpha}}{\left(\mathrm{C}_{\mathrm{y}} \cdot \mathrm{D}_{\mathrm{y}}+\varepsilon_{\mathrm{y}}\right)} \quad \mathrm{C}_{\mathrm{y}}=\mathrm{p}_{\mathrm{Cy} 1} \cdot \lambda_{\mathrm{Cy}} \square \quad \mathrm{D}_{\mathrm{y}}=\mu_{y} \cdot \mathrm{F}_{\mathrm{z}}
$$




$$
\begin{aligned}
& \left.\mu_{y}=\left\{\begin{array}{l}
\mathrm{p}_{\mathrm{Dy} 1} \cdot \exp \left(\mathrm{p}_{\mathrm{Dy} 2} \cdot \mathrm{df}\right. \\
\mathrm{z}
\end{array}\right) /\left(1+\mathrm{p}_{\mathrm{Dy} 3} \cdot \gamma_{\mathrm{y}}^{2}\right)\right\} \cdot \lambda_{\mu y}^{*} \quad \mathrm{df}_{z}=\frac{\mathrm{F}_{\mathrm{z}}-\lambda_{F_{z} 0} \cdot \mathrm{F}_{\mathrm{z} 0}}{\lambda_{F_{z 0}} \cdot \mathrm{F}_{\mathrm{z} 0}} \quad \mathrm{E}_{y}=\left(\mathrm{p}_{\mathrm{Ey} 1}+\mathrm{p}_{\mathrm{Ey} 2} \cdot \gamma_{y}^{2}+\left(\mathrm{p}_{\mathrm{Ey} 3}+\mathrm{p}_{\mathrm{Ey} 4} \cdot \gamma_{y}\right) \cdot \operatorname{sgn} \alpha_{y}\right) \cdot \lambda_{\mathrm{Ey}} \\
& \mathrm{K}_{y \alpha}=\mathrm{K}_{y \alpha 0} /\left(1+\mathrm{p}_{\mathrm{Ky} 5} \cdot \gamma_{y}^{2}\right) \quad \mathrm{K}_{y \alpha 0}=\mathrm{p}_{\mathrm{Ky} 1} \cdot \mathrm{F}_{\mathrm{z} 0} \cdot \lambda_{\mathrm{F}_{\mathrm{z}} 0} \sin \left[\mathrm{p}_{\mathrm{Ky} 2} \cdot \arctan \left\{\frac{\mathrm{F}_{\mathrm{z}}}{\left(\mathrm{p}_{\mathrm{Ky} 3}+\mathrm{p}_{\mathrm{Ky} 4} \cdot \gamma_{y}^{2}\right) \cdot \mathrm{F}_{\mathrm{z} 0} \cdot \lambda_{\mathrm{F} z 0}}\right\}\right] \cdot \lambda_{\mathrm{Ky} \alpha} \\
& \mathrm{B}_{\gamma}=\frac{\mathrm{K}_{y \gamma}}{\left(\mathrm{C}_{\gamma} \cdot \mathrm{D}_{y}+\varepsilon_{\mathrm{y}}\right)} \quad \mathrm{C}_{\gamma}=\mathrm{p}_{\mathrm{Cy} 2} \cdot \lambda_{C \gamma} \quad \mathrm{E}_{\gamma}=\mathrm{p}_{\mathrm{Ey} 5} \cdot \lambda_{\mathrm{E} \gamma} \quad \mathrm{S}_{H y}=\mathrm{p}_{\mathrm{Hy} 1} \cdot \lambda_{\mathrm{Hy}} \quad \mathrm{K}_{y \gamma}=\left(\mathrm{p}_{\mathrm{ky} 6}+\mathrm{p}_{\mathrm{ky} 7} \cdot \mathrm{df}_{z}\right) \cdot \mathrm{F}_{\mathrm{z}} \cdot \lambda_{k y \gamma}
\end{aligned}
$$

\section{Pacejka's Parameters}

$\gamma:$ Camber angle of the wheel from the ground

$\alpha^{*}$ : Tangent of the slip angle defined as the lateral slip

$\mathrm{k}$ : longitudinal slip

$\mathrm{F}_{\mathrm{z0}}$ : nominal (rated) load

$\mathrm{F}_{\mathrm{z}}$ : vertical load $\mathrm{F}_{\mathrm{z}}=\mathrm{F}_{\mathrm{z} 0} \pm \Delta \mathrm{F}_{\mathrm{z}}$

$\varepsilon_{\mathrm{y}}:$ Reduction factor

$\lambda_{\gamma y}:$ Scaling factor of camber force stiffness

$\lambda_{\text {cy }}:$ Scaling factor of $\mathrm{C}_{\mathrm{y}}$ shape factor

$\lambda_{\mu y}^{*}$ : The composite friction scaling factor in y direction

$\lambda_{\text {Ey }}$ : Scaling factor of $E_{\mathrm{y}}$ curvature factor

$\lambda_{\mathrm{E} \gamma}$ : Scaling factor of $\mathrm{E}_{\gamma}$ curvature factor

$\lambda_{\mathrm{Hy}}:$ Scaling factor of horizontal shift

$\lambda_{\mathrm{F}_{\mathrm{z} 0}}$ : Scaling factor of nominal (rated) load

$\lambda_{\mathrm{c} \gamma}:$ Scaling factor of $\mathrm{C}_{\gamma}$ shape factor

$\lambda_{\mathrm{Ky} \alpha}:$ Scaling factor of cornering stiffness

$\lambda_{\mathrm{Ky} \gamma}$ : Scaling factor of camber force stiffness

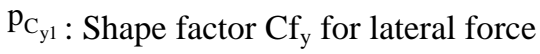

$\mathrm{p}_{\mathrm{C}_{\mathrm{y} 2}}$ : Shape factor $\mathrm{Cf}_{\mathrm{c}}$ for camber force

$\mathrm{p}_{\mathrm{D}_{\mathrm{y} 1}: \text { Lateral friction } \mu_{\mathrm{x}}}$

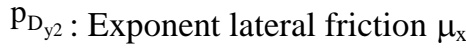

$\mathrm{p}_{\mathrm{D}_{\mathrm{y} 3}}$ : Variation of friction $\mu_{\mathrm{x}}$ with squared camber

$\mathrm{p}_{\mathrm{E}_{\mathrm{y} 1}}$ : Lateral curvature $\mathrm{Ef}_{\mathrm{y}}$ at $\mathrm{F}_{\mathrm{znom}}$

$\mathrm{p}_{\mathrm{E}_{\mathrm{y} 2}}$ : Variation of curvature $\mathrm{Ef}_{\mathrm{y}}$ with camber squared

$\mathrm{p}_{\mathrm{E}_{\mathrm{y}}}$ : Asymmetric curvature $\mathrm{Ef}_{\mathrm{y}}$ at $\mathrm{F}_{\mathrm{znom}}$

$\mathrm{p}_{\mathrm{E} 4}$ : Asymmetric curvature $\mathrm{Ef}_{\mathrm{y}}$ with camber

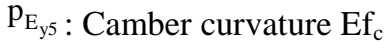

$\mathrm{p}_{\mathrm{H}_{\mathrm{y} 1}}$ : Horizontal shift shy at $\mathrm{F}_{\mathrm{znom}}$

$\mathrm{p}_{\mathrm{K}_{\mathrm{y} 1}}$ : Maximum value of stiffness $\mathrm{Kf}_{\mathrm{y}} / \mathrm{F}_{\mathrm{znom}}$

$\mathrm{p}_{\mathrm{K}_{\mathrm{y} 2}}$ : Curvature of stiffness $\mathrm{Kf}_{\mathrm{y}}$

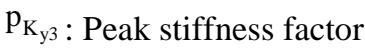

$\mathrm{p}_{\mathrm{K}_{\mathrm{y} 4}}$ : Peak stiffness variation with camber squared

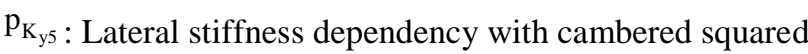




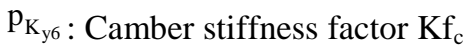

$\mathrm{p}_{\mathrm{K}_{\mathrm{y}}}$ : Vertical load dependency of camber stiffness $\mathrm{Kf}_{\mathrm{c}}$

\section{B Parameters}

The indices are defined as follows: front $(i=1)$, rear $(i=2)$, left $(j=1)$, right $(j=2)$

$\theta$ : roll angle

$\psi$ : yaw angle

$\delta$ : side slip angle to the centre of gravity of the vehicle

$\gamma_{t}$ : transverse acceleration of the centre of gravity

g: gravity acceleration

$\mathrm{V}$ : vehicle speed

$\mathrm{M}$ : mass of the vehicle

$\mathrm{I}_{\mathrm{x}}, \mathrm{I}_{\mathrm{y}}, \mathrm{I}_{\mathrm{z}}, \mathrm{I}_{\mathrm{xz}}$ : Axial mass inertia moments of the vehicle through the centre of gravity

$\mathrm{l}_{\mathrm{i}}$ : distance between the centre of gravity and the front or rear axle

$\mathrm{h}$ : height of the centre of gravity from the ground

$\mathrm{s}_{\mathrm{i}}$ : height of the axle roll centre from the ground

$\mathrm{e}_{\mathrm{i}}$ : front or rear axle track

$\mathrm{n}$ : gear ratio

$\alpha_{\mathrm{v}}$ : steering wheel angle

$\alpha_{1 \mathrm{j}}$ : steering angle of the left or right wheel for the front axle

$A_{i}$ : suspension damper for the front or rear axle

$\varepsilon_{\mathrm{i}}$ : Steering coefficient induced by the front or rear roll

$\mathrm{c}_{1}$ : linear caster on the ground for the front axle

$\mathrm{C}_{\mathrm{i} \theta}$ : anti-roll stiffness of the front or rear axle

$\mathrm{C}_{\mathrm{bad}}$ : stiffness of anti-roll bar for the front or rear axle

$\mathrm{k}_{\mathrm{i}}$ : linear stiffness of suspension springs for the front or rear axle

$\lambda_{\mathrm{i}}$ : camber coefficient induced by the front or rear roll

$b_{i}$ : sway radius of the front or rear axle

$\delta_{\mathrm{i}}$ : side slip angle for the front or rear axle

$\delta_{\mathrm{ij}}$ : left or right wheel side slip angle for the front or rear axle

$\gamma_{\text {wheel }_{\mathrm{ij}} / \text { ground }}$ : camber angle between the wheel $\mathrm{j}$ of the axle $\mathrm{i}$ and the ground

$\gamma_{\text {wheel }_{\mathrm{ij}} / \mathrm{axle}_{\mathrm{i}}}$ : camber angle between the wheel $\mathrm{j}$ of the axle $\mathrm{i}$ and the axle $\mathrm{i}$

$\mathrm{a}_{\mathrm{i}}$ : front or rear tyres caster

$k_{\text {tyre } i}:$ stiffness of tyres for the front or rear axle

$\mathrm{P}_{\mathrm{i}}$ : camber load coefficient for the front or rear axle 
$\mathrm{D}_{\mathrm{i}}$ : side slip rigidity of the front or rear axle

$\mathrm{Y}_{\mathrm{ij}}$ Lateral force for the left or right wheel of the front or rear axle

C- The "4-wheel roll / yaw / side slip" model with camber contribution $\mathrm{M} \gamma_{\mathrm{t}}-\sum_{\mathrm{i}=1}^{2} \sum_{\mathrm{j}=1}^{2} \mathrm{Y}_{\mathrm{ij}}=0$

$\mathrm{I}_{\mathrm{x}} \ddot{\theta}-\mathrm{I}_{\mathrm{xz}} \ddot{\psi}+\mathrm{C}_{\theta}^{\prime} \theta-\left(\mathrm{A}_{1}+\mathrm{A}_{2}\right) \dot{\theta}-\sum_{\mathrm{i}=1}^{2} \mathrm{~h}_{\mathrm{i}} \cdot \sum_{\mathrm{j}=1}^{2} \mathrm{Y}_{\mathrm{ij}}=0$

$\mathrm{I}_{\mathrm{z}} \ddot{\psi}-\mathrm{I}_{\mathrm{xz}} \ddot{\theta}-\sum_{\mathrm{i}=1}^{2}\left(\mathrm{l}_{\mathrm{i}}-\mathrm{a}_{\mathrm{i}}\right) \cdot \sum_{\mathrm{j}=1}^{2} \mathrm{Y}_{\mathrm{ij}}=0 \quad \gamma_{\mathrm{t}}-\mathrm{V} \cdot(\dot{\psi}-\dot{\delta})=0$

$\mathrm{V} \cdot\left(\alpha_{11}+\varepsilon_{1} \cdot \theta+\delta_{11}-\delta\right)-\left(\mathrm{l}_{1}-a_{1}\right) \cdot \dot{\psi}-\mathrm{h}_{1} \cdot \dot{\theta}+\mathrm{b}_{1} \cdot \dot{\delta}_{11}+\left(c_{1}+a_{1}\right)\left(\dot{\alpha}_{11}+\dot{\theta} \cdot \varepsilon_{1}\right)=0$

$\mathrm{V} .\left(\alpha_{12}+\varepsilon_{1} \cdot \theta+\delta_{12}-\delta\right)-\left(\mathrm{l}_{1}-a_{1}\right) \cdot \dot{\psi}-\mathrm{h}_{1} \cdot \dot{\theta}+\mathrm{b}_{1} \cdot \dot{\delta}_{12}+\left(c_{1}+a_{1}\right)\left(\dot{\alpha}_{12}+\dot{\theta} \cdot \varepsilon_{1}\right)=0$

$\mathrm{V} .\left(\varepsilon_{2} \cdot \theta+\delta_{21}-\delta\right)+\left(1_{2}+a_{2}\right) \cdot \dot{\psi}-\mathrm{h}_{2} \cdot \dot{\theta}+\mathrm{b}_{2} \cdot \dot{\delta}_{21}+a_{2}\left(\dot{\theta} \cdot \varepsilon_{2}\right)=0$

$\mathrm{V} .\left(\varepsilon_{2} \cdot \theta+\delta_{22}-\delta\right)+\left(\mathrm{l}_{2}+a_{2}\right) \cdot \dot{\psi}-\mathrm{h}_{2} \cdot \dot{\theta}+\mathrm{b}_{2} \cdot \dot{\delta}_{22}+a_{2}\left(\dot{\theta} \cdot \varepsilon_{2}\right)=0$

$\mathrm{Y}_{11}+\mathrm{D}_{1} \cdot \delta_{11}+\mathrm{P}_{1} \cdot \gamma_{\text {wheel }_{11} / \text { ground }}=0 \quad \mathrm{Y}_{12}+\mathrm{D}_{1} \cdot \delta_{12}+\mathrm{P}_{1} \cdot \gamma_{\text {wheel }_{12} / \text { ground }}=0$

$\mathrm{Y}_{21}+\mathrm{D}_{2} \cdot \delta_{21}+\mathrm{P}_{2} \cdot \gamma_{\text {whee }_{21} / \text { ground }}=0 \quad \mathrm{Y}_{22}+\mathrm{D}_{2} \cdot \delta_{22}+\mathrm{P}_{2} \cdot \gamma_{\text {wheel }_{22} / \text { ground }}=0$

$\gamma_{\text {wheel }_{11} / \text { ground }}=\gamma_{\text {wheel }_{11} / \text { axle }_{1}}-\lambda_{1} \cdot \theta \quad \gamma_{\text {wheel }_{12} / \text { ground }}=\gamma_{\text {wheel }_{12} / \text { axle }_{1}}-\lambda_{1} \cdot \theta$

$\gamma_{\text {wheel }_{21} / \text { ground }}=\gamma_{\text {wheel }_{21} / \text { axle }_{2}}-\lambda_{2} \cdot \theta \quad \gamma_{\text {wheel }_{22} / \text { ground }}=\gamma_{\text {wheel }_{22} / \text { axle }_{2}}-\lambda_{2} \cdot \theta$

$\mathrm{C}_{\theta}^{\prime}=\mathrm{C}_{1 \theta}+\mathrm{C}_{2 \theta}-$ M.g.h.h

$\mathrm{h}_{0}^{\prime}=\frac{\mathrm{h}_{1} \cdot \mathrm{l}_{2}^{\prime}+\mathrm{h}_{2} \cdot \mathrm{l}_{1}^{\prime}}{\mathrm{l}_{1}^{\prime}+\mathrm{l}_{2}^{\prime}} \quad \mathrm{l}_{1}^{\prime}=\mathrm{l}_{1}-\mathrm{a}_{1} \quad \mathrm{l}_{2}^{\prime}=\mathrm{l}_{2}+\mathrm{a}_{2} \quad \mathrm{~h}_{1}=\mathrm{h}-\mathrm{s}_{1} \quad \mathrm{~h}_{2}=\mathrm{h}-\mathrm{s}_{2}$

$\mathrm{C}_{1 \theta}=\frac{1}{4} \mathrm{k}_{1} \cdot \mathrm{e}_{1}^{2}+\mathrm{C}_{\mathrm{bad} 1} \quad \mathrm{C}_{2 \theta}=\frac{1}{4} \mathrm{k}_{2} \cdot \mathrm{e}_{2}^{2}+\mathrm{C}_{\mathrm{bad} 2} \quad \alpha_{11}=\mathrm{n} \alpha_{\mathrm{v}} \quad \alpha_{12}=\mathrm{n} \alpha_{\mathrm{v}}$ 


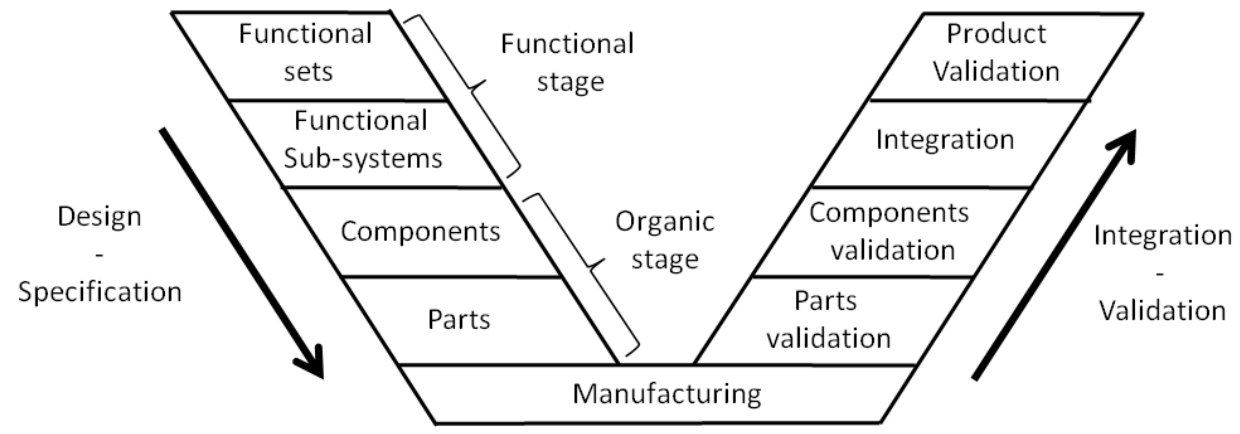

Figure 1. V-shaped cycle

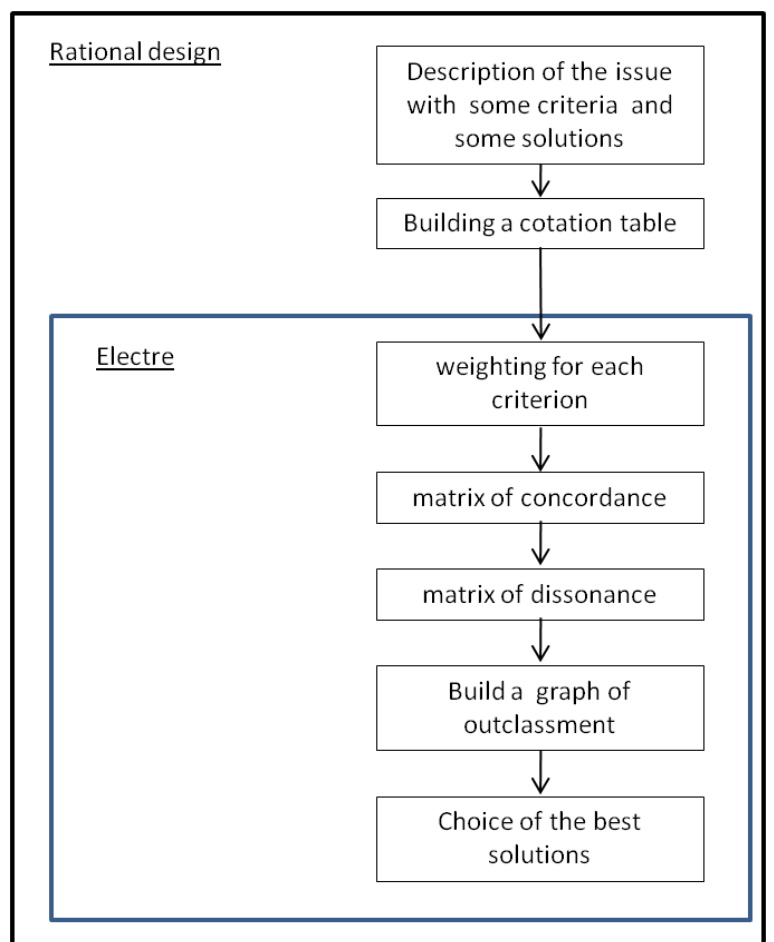

Figure 2. "Rational Design - Electre " method

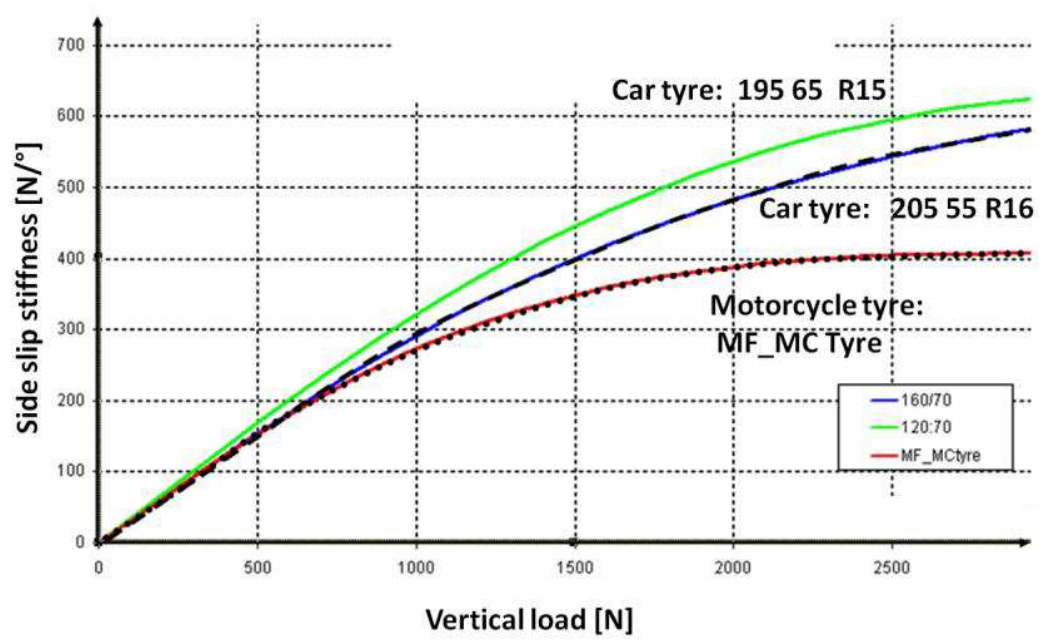

Figure 3. Comparison of car and motorcycle tyres 


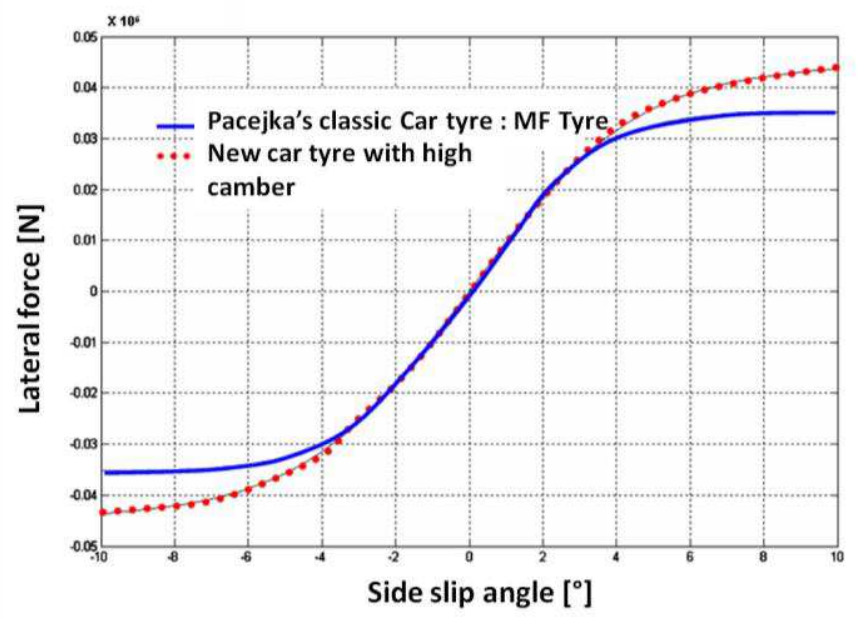

Figure 4. Retiming: -a- lateral force vs. side slip

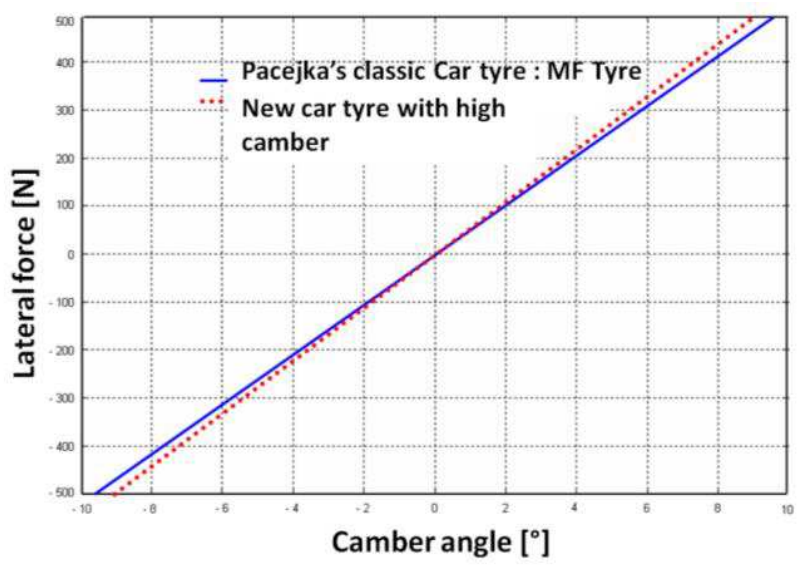

Figure 4. Retiming: -b- lateral force vs. camber angle

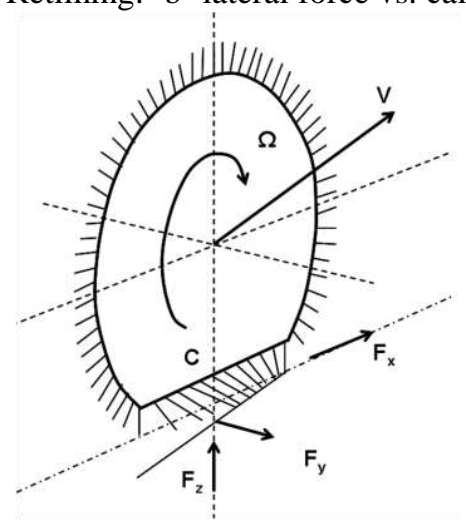

Figure 5. Brush model 


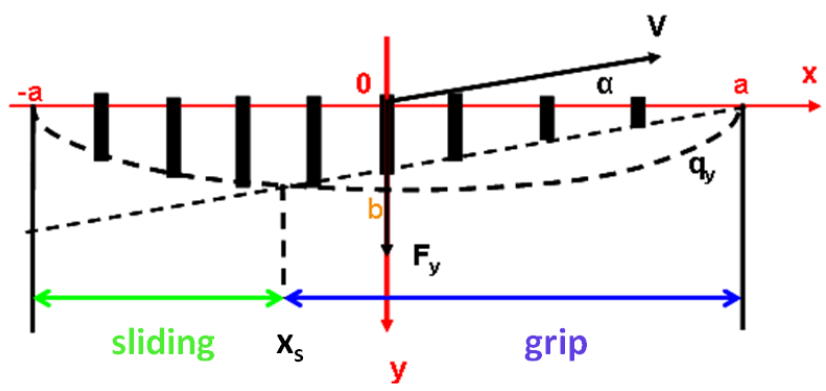

Length of the contact area : $2 \mathrm{a}$

Width of the contact area : $\mathbf{2 b}$

Figure 6. Brush model (pure side slip)

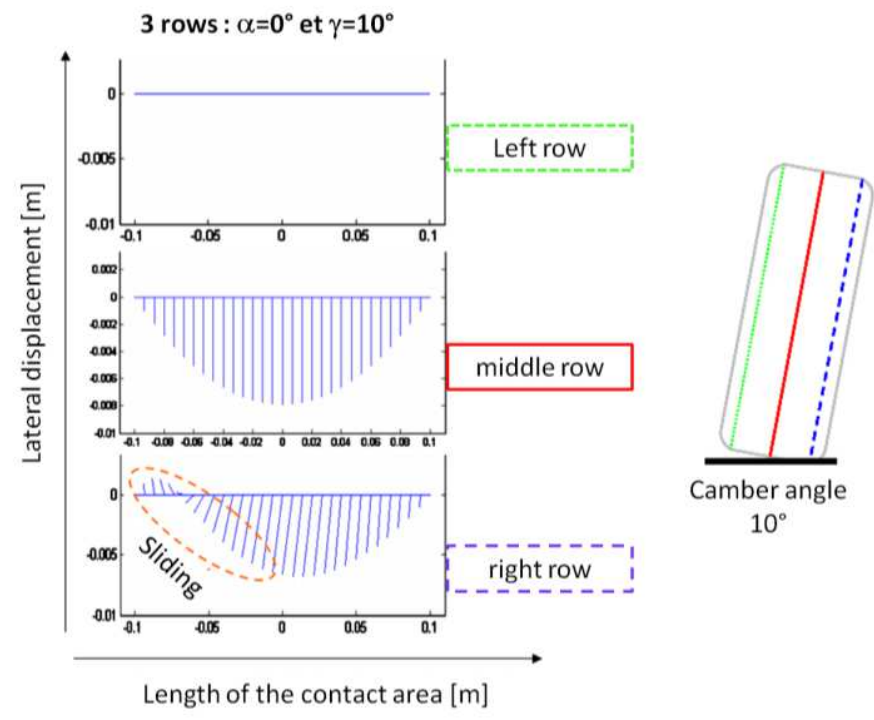

Figure 7. Deformation of three rows of a tyre

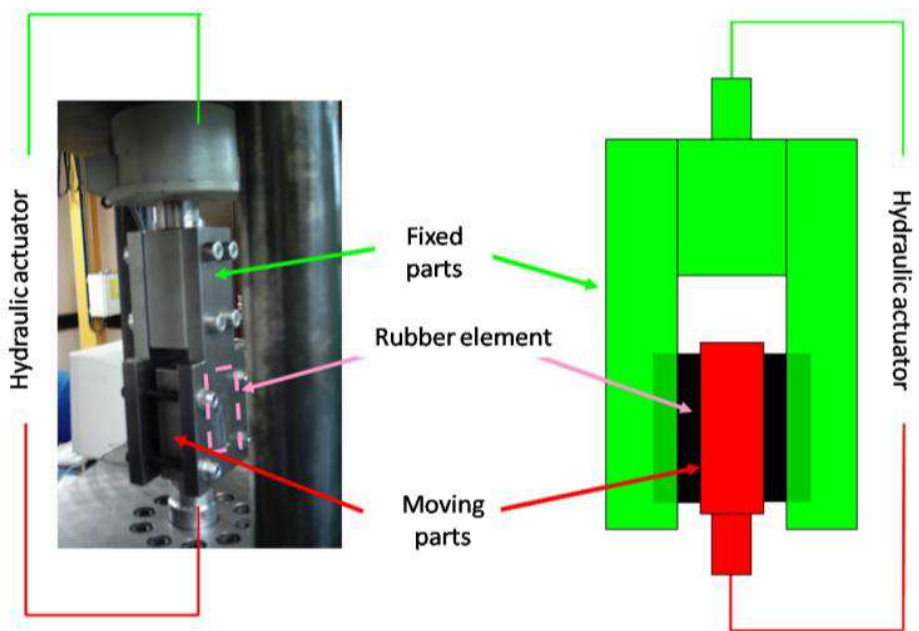

Figure 8. Shear bench 

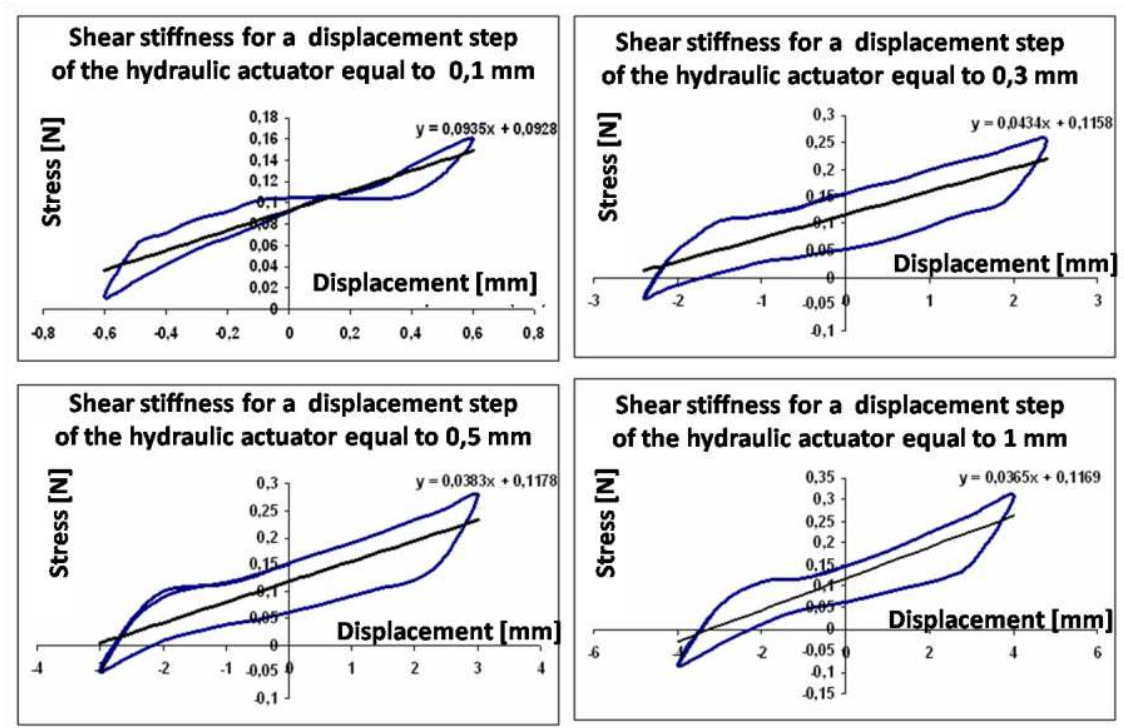

Figure 9. Transverse shear stiffnesses

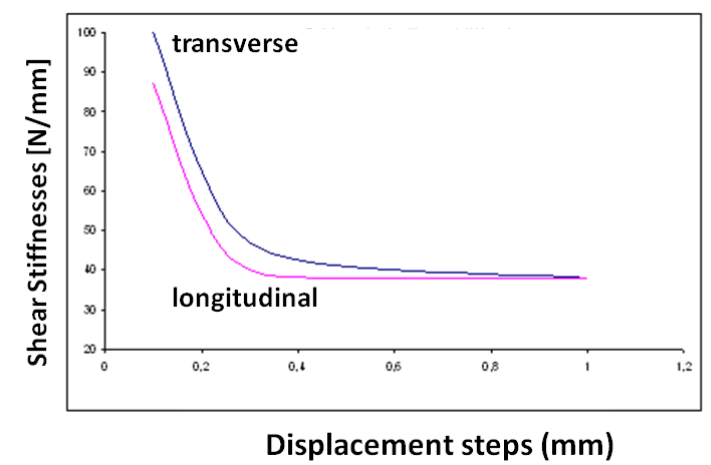

Figure 10. Shear stiffnesses vs displacement steps

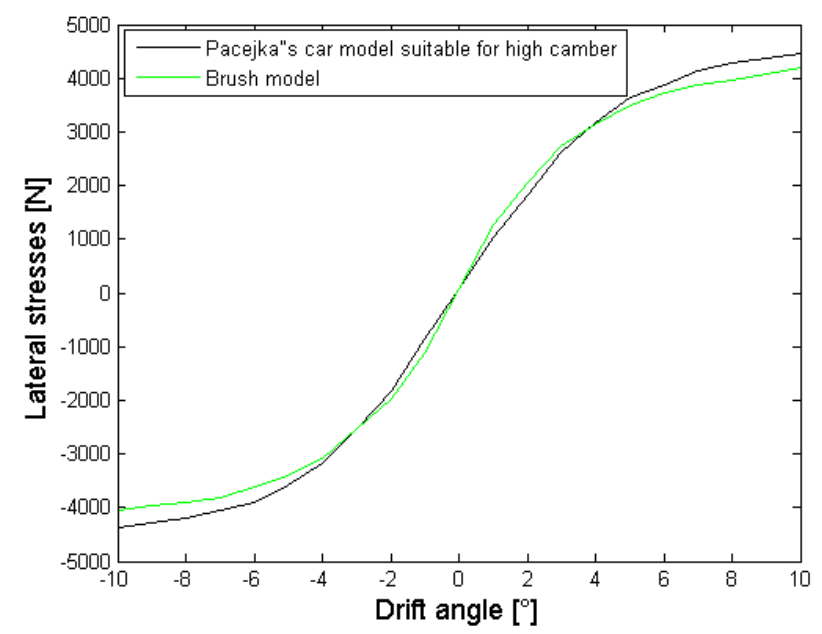

Figure 11. Correlation: -a- Pacejka's car model with high camber and brush model: lateral forces vs side slip 


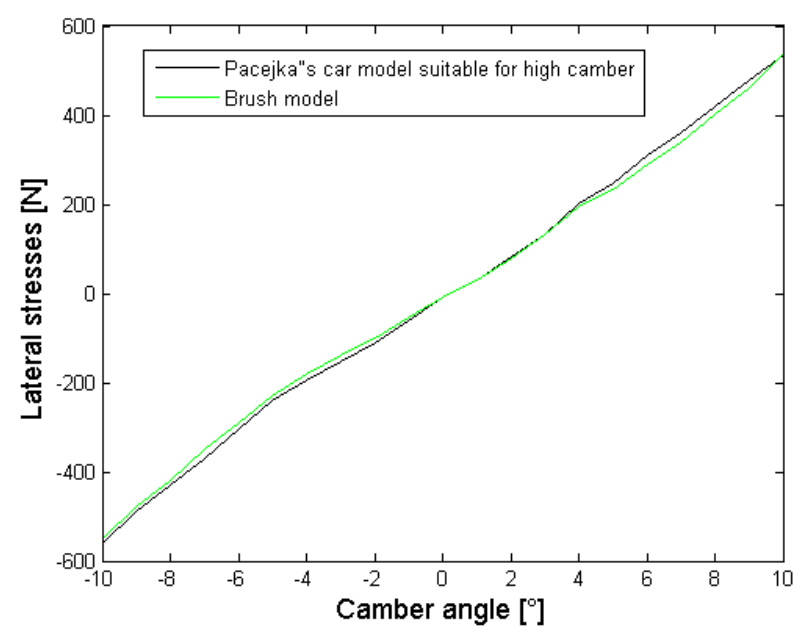

Figure 11. Correlation: -b- Pacejka's car model with high camber and brush model: lateral forces vs camber angle

Vehicle Dynamics

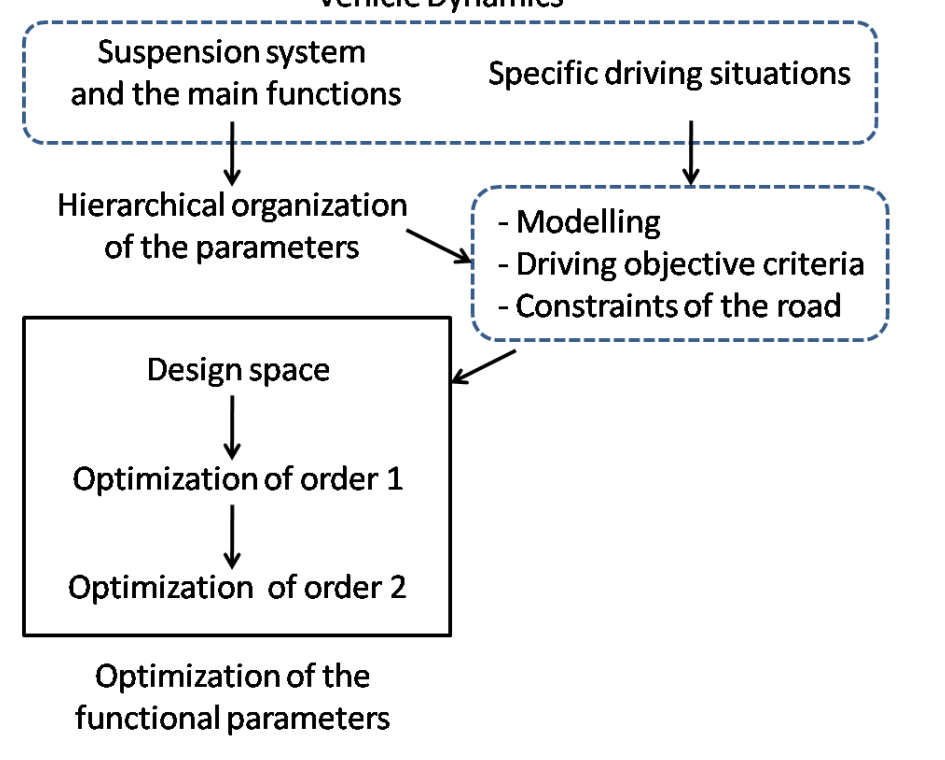

Figure 12. The functional phase

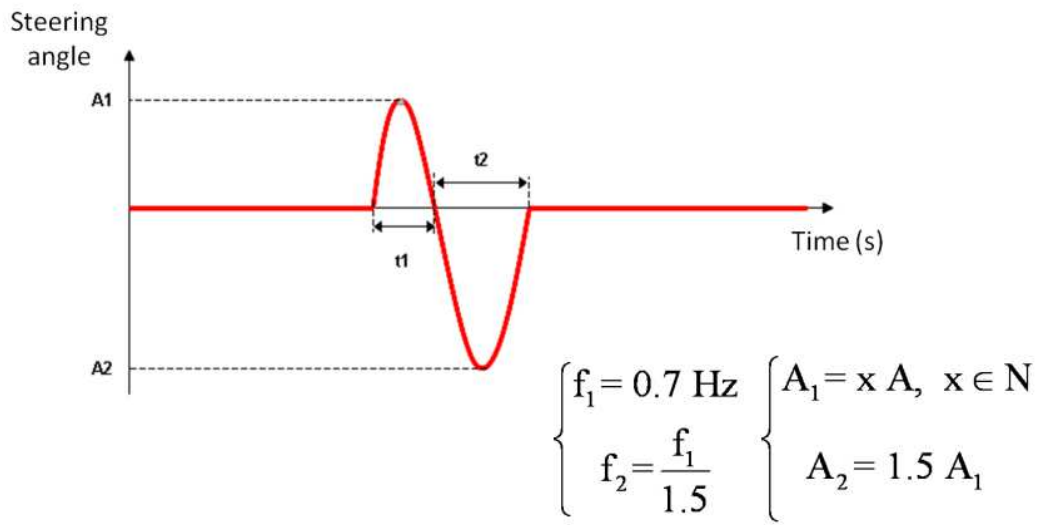

Figure 13. Sinus Ford 


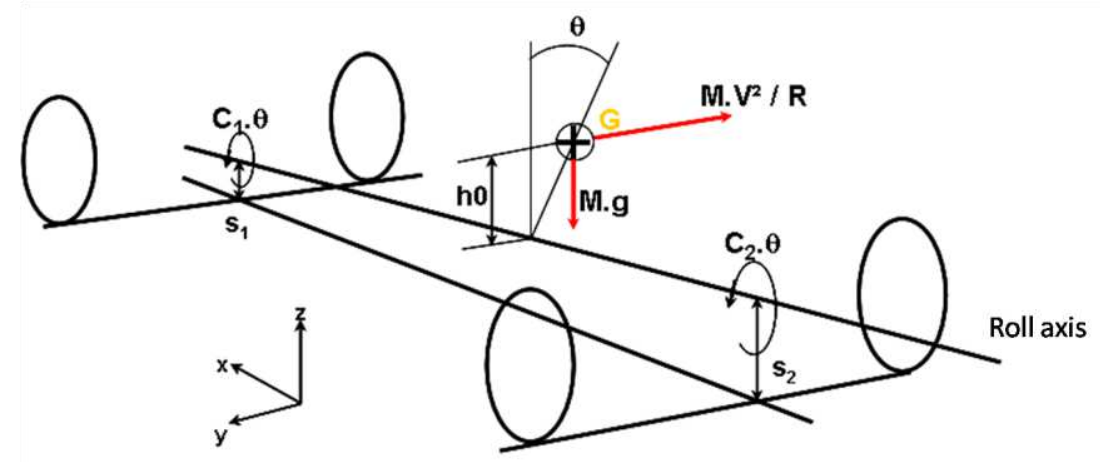

Figure 14. "4-wheel roll / yaw / side slip" model with camber contribution

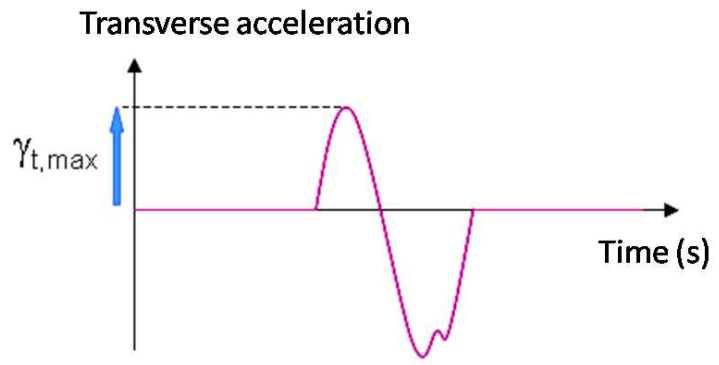

Figure 15. Sinus Ford: effectiveness criterion Side slip to the centre of gravity

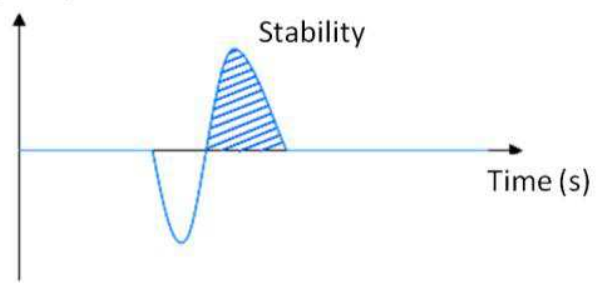

Figure 16. Sinus Ford: stability criterion
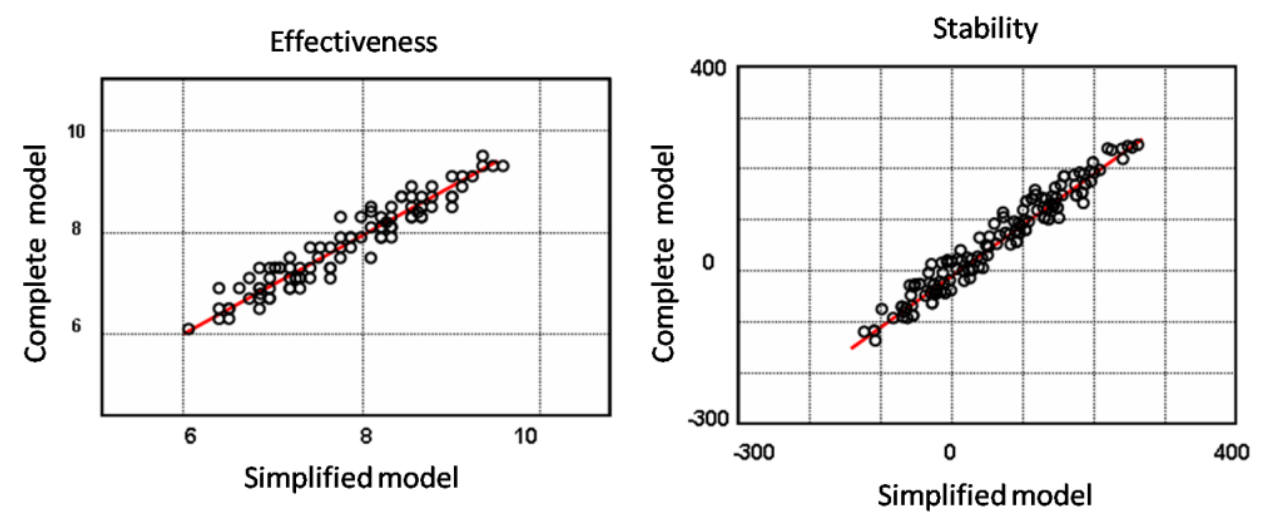

Figure 17. Correlation of the simplified model and the complete model (MADA): sinus Ford 

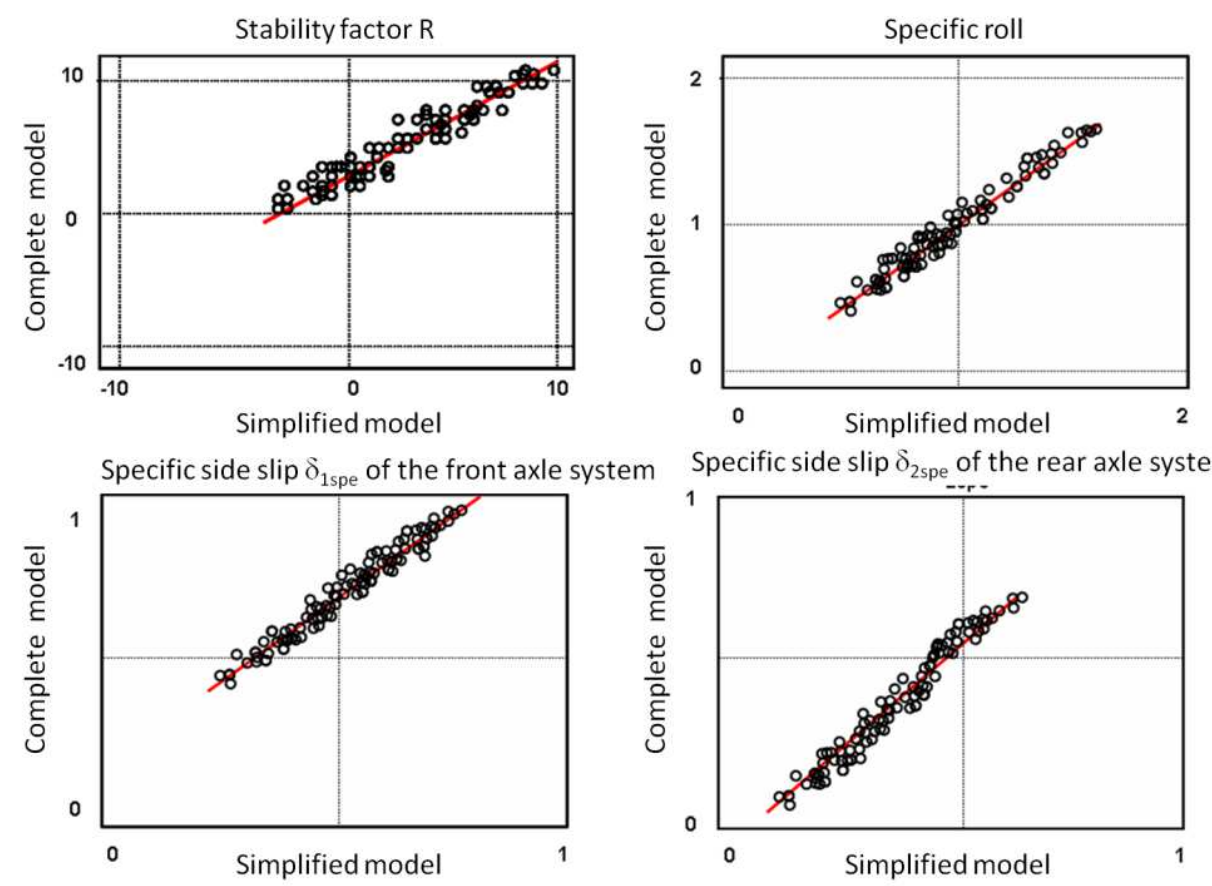

Figure 18. Correlation of the simplified model and the complete model (MADA): steady state cornering.

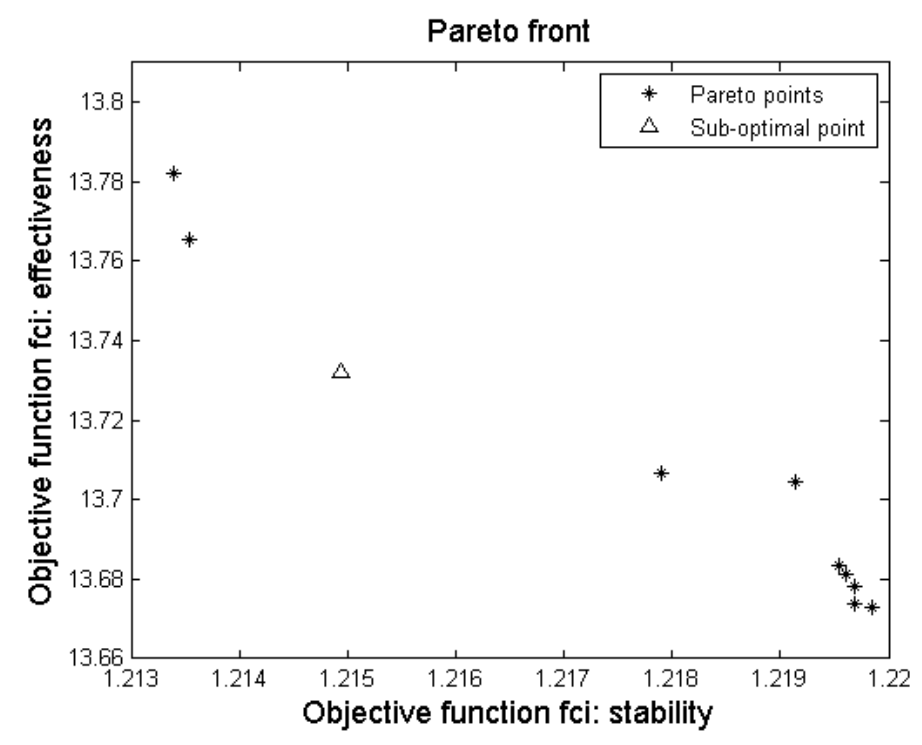

Figure 19. Pareto front: -a- sinus Ford 


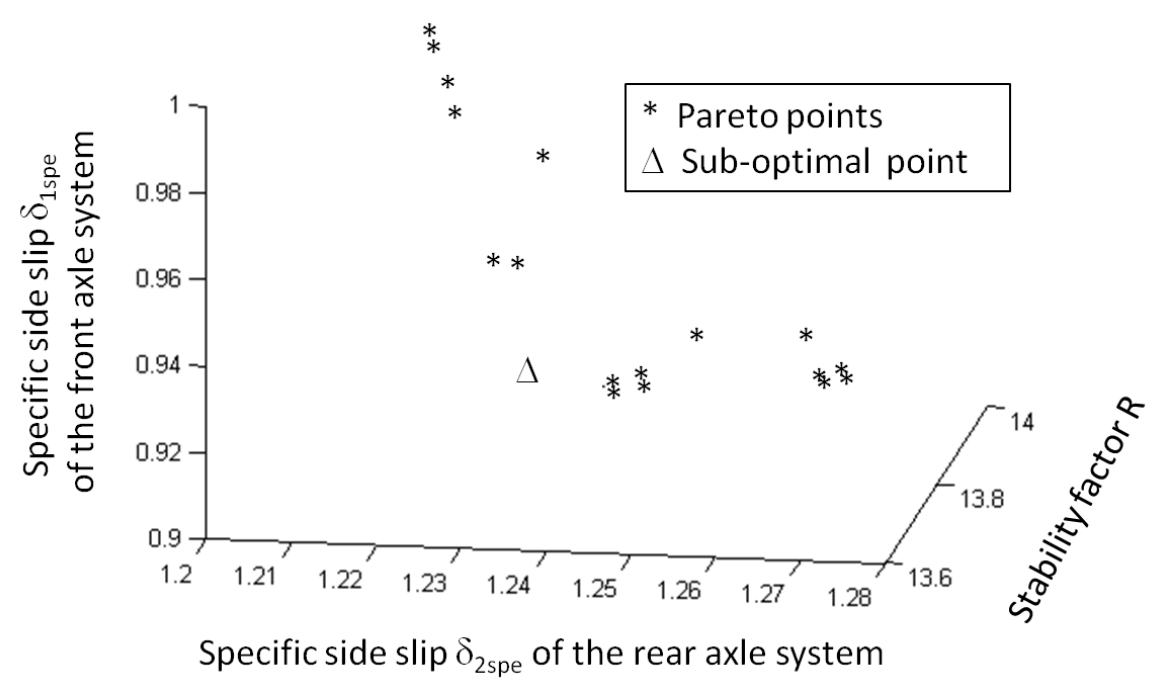

Figure 19. Pareto front: -b- steady state cornering.

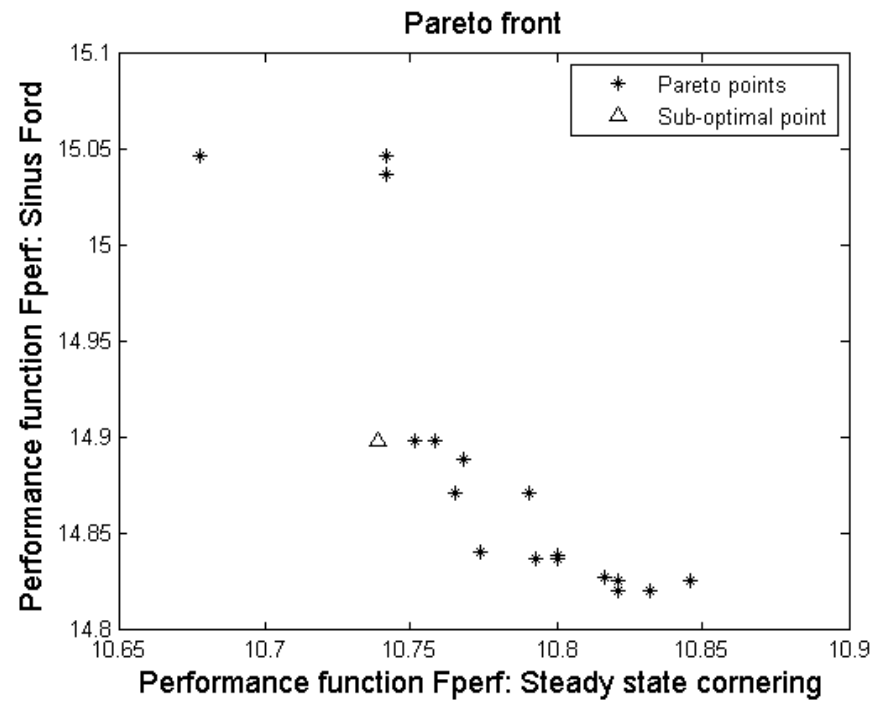

Figure 20. Pareto front - trade-off sinus ford / steady state cornering.
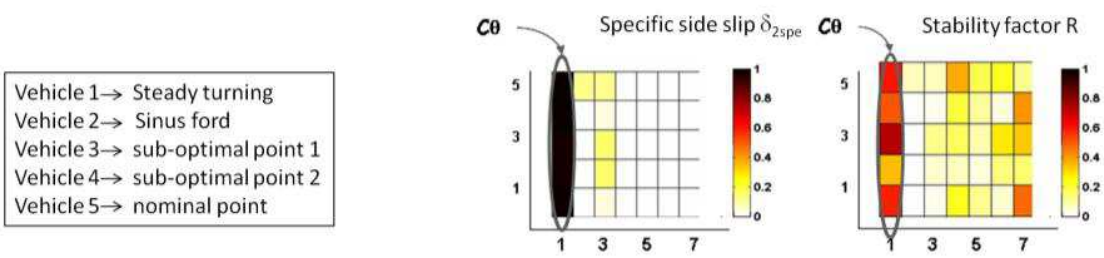

$$
\begin{aligned}
& 1 \rightarrow \text { total roll stiffness } C_{\theta} \\
& 2 \rightarrow \text { height of the front roll centre } \\
& 3 \rightarrow \text { height of the rear roll centre } \\
& 4 \rightarrow \text { Camber coefficient induced by the rear roll } \\
& 5 \rightarrow \text { Camber coefficient induced by the front roll } \\
& 6 \rightarrow \text { Steering coefficient induced by the rear roll } \\
& 7 \rightarrow \text { Steering coefficient induced by the front roll }
\end{aligned}
$$
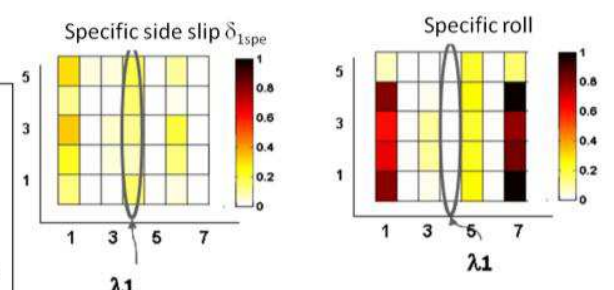

Figure 21. Steady state cornering.: evaluation of the robustness of 7 criteria for 5 selected vehicles 


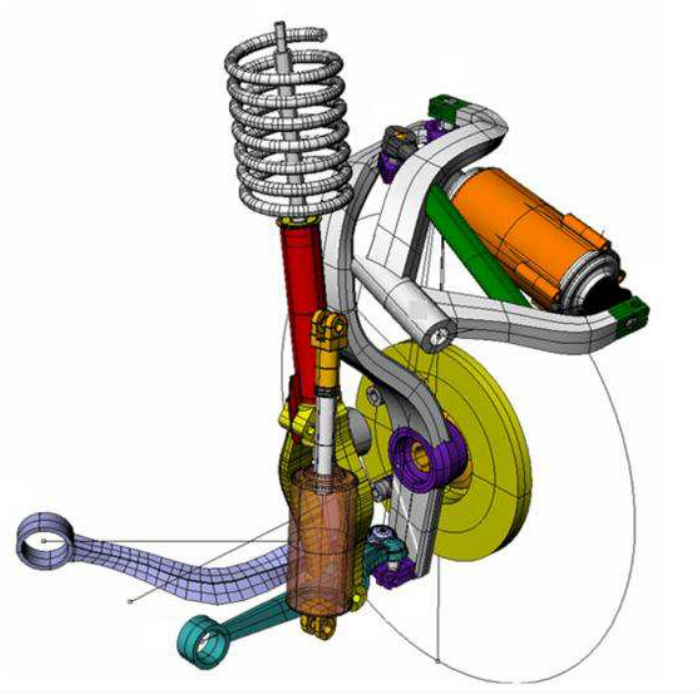

Figure 22. The double wishbone axle with a semi-fictitious pivot (Patent No. FR2890631)

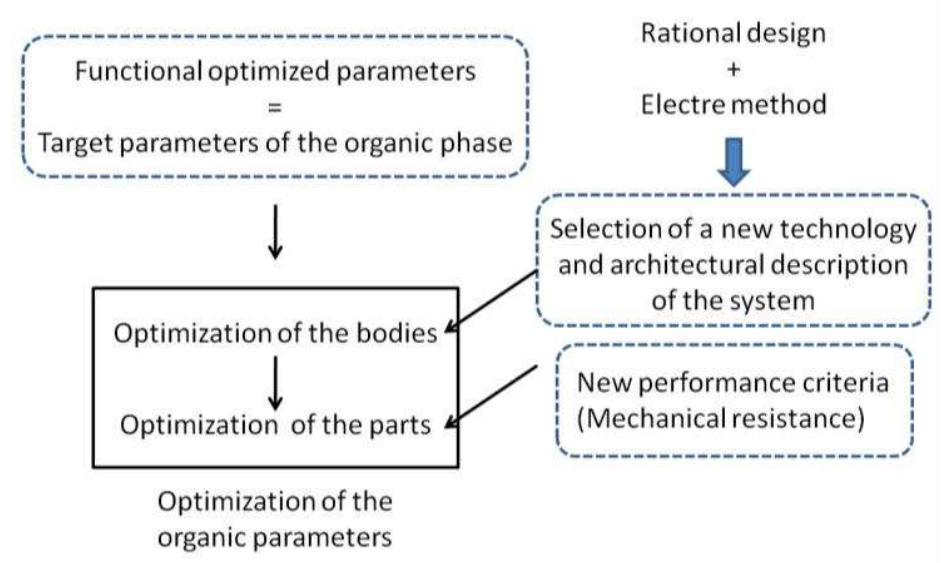

Figure 23. The organic phase

\begin{tabular}{|c|c|c|c|}
\hline & Solution1 & Solution 2 & Solution 3 \\
\hline Dynamic behaviour & & & \\
\hline $\begin{array}{c}\text { Mastery of the camber } \\
\text { variation in pumping }\end{array}$ & 1 & 0 & 1 \\
\hline Durability (tyre wear ) & 1 & 1 & 1 \\
\hline Camber angle potential & 0 & -1 & 1 \\
\hline Technical constraints & & & \\
\hline Actuators number & -1 & -1 & 1 \\
\hline
\end{tabular}

Table 1. Quotation table of Rational Design method for the suspension system 